\title{
Financial Constraints, Intangible Assets, and Firm Dynamics: Theory and Evidence
}


Financial Constraints, Intangible Assets, and Firm Dynamics: Theory and Evidence

Sophia Chen 


\title{
IMF Working Paper
}

\author{
Research Department
}

\begin{abstract}
Financial Constraints, Intangible Assets, and Firm Dynamics: Theory and Evidence ${ }^{1}$ Prepared by Sophia Chen
\end{abstract}

Authorized for distribution by Giovanni Dell'Ariccia

May 2014

\section{This Working Paper should not be reported as representing the views of the IMF.} The views expressed in this Working Paper are those of the author(s) and do not necessarily represent those of the IMF or IMF policy. Working Papers describe research in progress by the author(s) and are published to elicit comments and to further debate.

\begin{abstract}
I study whether firms' reliance on intangible assets is an important determinant of financing constraints. I construct new measures of firm-level physical and intangible assets using accounting information on U.S. public firms. I find that firms with a higher share of intangible assets in total assets start smaller, grow faster, and have higher Tobin's q. Asset tangibility predicts firm dynamics and Tobin's q up to 30 years but has diminishing predicative power. I develop a model of endogenous financial constraints in which firm size and value are limited by the enforceability of financial contracts. Asset tangibility matters because physical and intangible assets differ in their residual value when the contract is repudiated. This mechanism is qualitatively important to explain stylized facts of firm dynamics and Tobin's q.
\end{abstract}

JEL Classification Numbers: E22, E44, D21, G3

Keywords: Financial constraints, intangible assets, firm dynamics, Tobin's q Author's E-Mail Address:YChen2@imf.org

\footnotetext{
${ }^{1}$ I am very grateful to Dmitriy Stolyarov for his constant guidance and encouragement on this project. I also thank Giovanni Dell'Ariccia, Kathryn Dominguez, Christopher House, Luc Laeven, John Laitner, and participants of various seminars and conferences for their valuable suggestions and comments.
} 


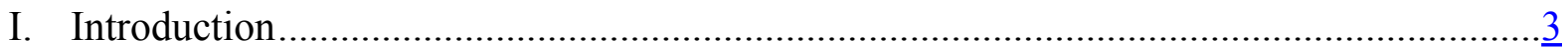

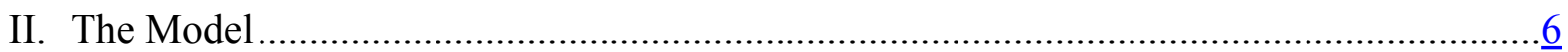

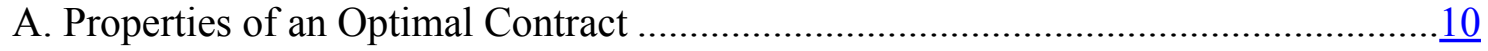

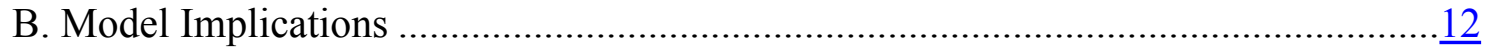

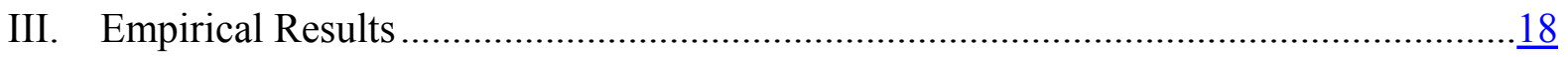

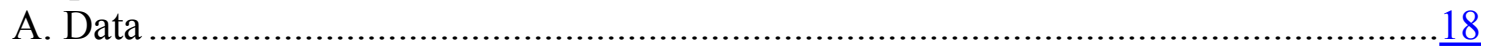

B. Empirical Findings and Tests of Model Implications …...................................

IV. Conclusion ................................................................................................... 24

Tables

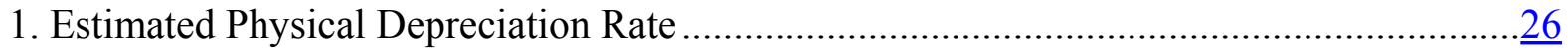

2. Entrant Asset Tangibility, Firm Dynamics, and Q ............................................... 27

3. The Age Effects of Asset Tangibility on Firm Size.................................................... 29

4. The Age Effects of Asset Tangibility on Firm Growth and Q...................................... 30

Figures

1. Intangible Assets, Firm Dynamics, and Q: Stylized Facts............................................. $\underline{4}$

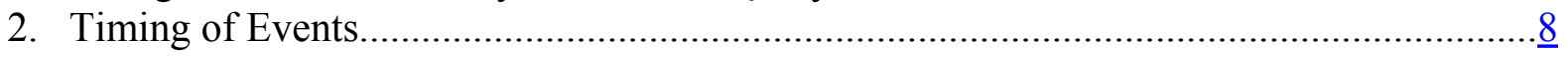

3. Tobin's Q and Intangible Adjusted Q: Data .............................................................14

4. Tobin's Q and Intangible Adjusted Q: Simulated Model ........................................... $\frac{15}{18}$

5. Intangible Asset, Firm Dynamics and Q: Simulated Model ....................................... $\frac{18}{21}$

6. Asset Tangibility Distribution Among Entrants .....................................................

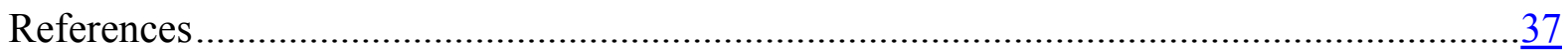




\section{INTRODUCTION}

External financing is an important determinant for the creation of new firms and the expansion of existing ones. ${ }^{1}$ One major obstacle to external financing is the enforceability of a financial contract. When a firm has the ability to repudiate a contract, optimal contractual arrangements may set endogenous financial constraints based on how much the firm can credibly repay.

Financial constraints, however, do not affect all firms equally. The financing of investment in intangible assets, such as research and development, employee training, and expenditures on marketing and strategy consultants, is more susceptible to financing frictions than investment in physical assets because of the inalienable and firm-specific nature of intangible assets. This paper presents evidence that the sensitivity of firm dynamics on financial constraints is determined by the firm's asset tangibility. The theoretical model offers detailed predictions on the dynamics of firms with heterogeneous technologies and assets, for which I find robust empirical support.

Empirically, financial constraints associated with intangible assets have short-run and longrun consequences, which I find nontrivial in magnitude. I construct new measures of firmlevel physical and intangible assets using accounting information on U.S. public firms from Compustat data. I find that firms with a higher share of intangible assets in total assets start smaller, grow faster, and have higher market value per unit of assets. Asset tangibility explains $34 \%$ of the variance in the size of physical assets of entrant firms, $13 \%$ of their variance in employment, $17 \%$ of their variance in assets growth, and $7 \%$ of their variance in the market value per unit of total assets. The predictive power remains strong for firms up to 30 years old; however, as firms age, asset tangibility eventually ceases to matter. It is worth noting that the market value per unit of fixed assets (i.e. Tobin's q) also falls with age among young firms. ${ }^{2}$ While Tobin's q levels off eventually, it does not converge among firms with different asset tangibility. This is in contrast with market value per unit of total assets (hereafter, intangible adjusted q), which converges among older firms. These patterns are summarized in Figure $1 .^{3}$

This paper provides a simple yet comprehensive model that explains these salient features of the data. I incorporate heterogeneous firms and dynamic investment decisions on physical and intangible assets into a model of limited contract enforcement based on Albuquerque and Hopenhayn (2004). Three assumptions underpin the model: (i) Young firms have insufficient internal funds and are partly financed by external debt. (ii) Financial frictions arise because debt contracts have limited enforceability and a repudiation-free contract sets an endogenous borrowing limit. (iii) Physical and intangible assets affect the borrowing limit asymmetrically because intangible assets have higher residual value for the firm if the debt contract is repudiated.

\footnotetext{
${ }^{1}$ See, for example, Meyer and Kuh (1957), Fazzari, Hubbard and Petersen (1988), and Stein (2003).

${ }^{2}$ Following conventions, the replacement value is measured by the book value of physical assets.

${ }^{3}$ The sample of firms is from the annual Standard and Poor's Compustat industrial file and the Center for Research in Security Prices (CRSP) monthly stock file. Physical and intangible assets are constructed from corresponding investment expenditure using a perpetual inventory method. See Section III for detailed descriptions of the data, variable measurement and results.
} 
Figure 1: Intangible Assets, Firm dynamics, and Q: Stylized Facts
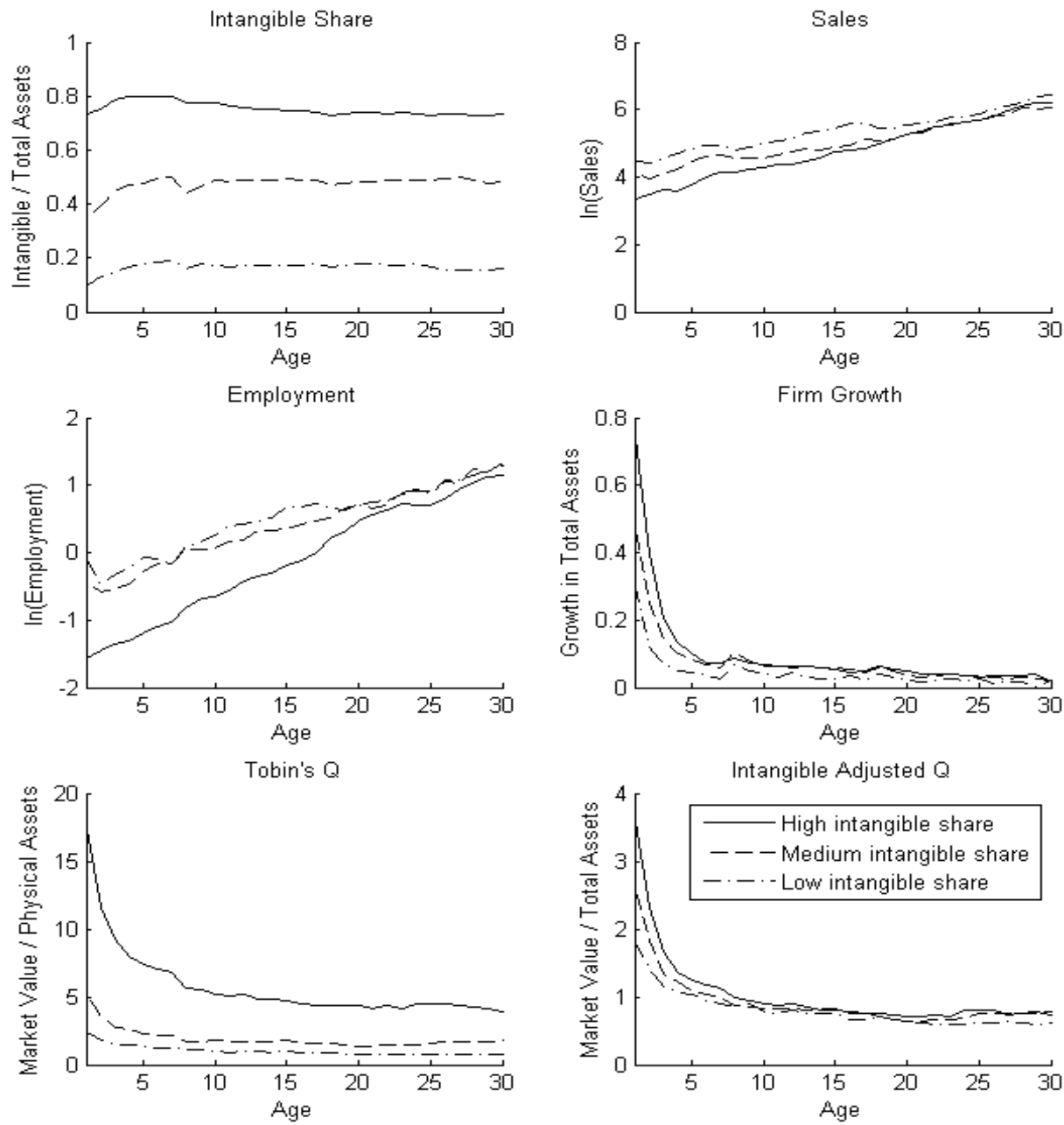
The inalienable and firm-specific features of intangible assets motivate the last two assumptions. Although a creditor may seize physical assets when the firm repudiates the contract, intangible assets tend to be inalienable from the owner of the firm, whether they are managerial skills developed by running the firm or patents in the name of the owner. Intangible assets are often specific to the firm, having large value inside the firm but little value to creditors. This feature of intangible assets also motivates the use of state-contingent debt contract, which distinguishes my model from models with collateral constraints. ${ }^{4}$ Although collateralized debt is the typical form of financing for certain firms, for firms that are intensive in intangible assets it is usually not available because of the specificity of their assets. Outside investors have to rely on direct contractual incentives.

My model offers an explanation for Figure 1 as follows. Young firms are unable to internally finance start-up costs and large investment expenditure. They rely on external debt contracts with an endogenous borrowing limit based on how much they can credibly repay. When firms are financially constrained, they have a high market value per unit of assets, reflecting their constrained size and future growth opportunities. As firms grow and pay off debt gradually, financial constraints are relaxed over time. In the model, heterogeneous financial constraints arise because firms have technologies that differ in the intensity of intangible assets. Firms whose technology depends more heavily on intangible assets face tighter borrowing limits. As a result, asset tangibility strongly correlates with young firms' size, growth, and market value, but it eventually ceases to matter as firms become financially unconstrained.

In the model, financial constraints lead to three sources of inefficiencies: First, they discourage the creation of firms whose technology relies heavily on intangible assets. Second, firms, particularly those that are intensive in intangible assets, are constrained to be inefficiently small for a prolonged period of time. Third, firms distort investment away from intangible assets, leading to misallocation between physical and intangible assets.

My theory of endogenous borrowing limits is most related to Albuquerque and Hopenhayn (2004). ${ }^{5}$ In their model, physical assets are short-lived and there is no intangible assets. My extensions are important for several reasons. Introducing long-lived assets is crucial for the model to generate the age dynamics of Tobin's q that are consistent with the data. Second, as a framework for the analysis of market value and Tobin's q, the introduction of intangible assets is very relevant. Finally, adding heterogeneity in firms' production technologies allows the model to offer an intuitive yet comprehensive explanation to the short-run and long-run effects of asset tangibility on firm dynamics, and to generate a new set of testable implications.

This paper relates in a broad sense to the literature on firm dynamics. Empirically, a large number of studies find that firm growth depends on firm age and size. ${ }^{6}$ Various studies provide explanations to these empirical regularities, such as learning or persistent shocks to the

\footnotetext{
${ }^{4}$ See, for example, Kiyotaki and Moore (1997).

${ }^{5}$ See, for example, Clementi and Hopenhayn (2006), Quadrini (2004), and Arellano, Bai and Zhang (Forthcoming), for related models on financial frictions and firm dynamics.

${ }^{6}$ See, among others, Evans (1987) and Hall (1987) for earlier results and Haltiwanger, Jarmin and Miranda (2010) for more recent findings.
} 
production technology. ${ }^{7}$ These models without financial frictions are successful in explaining unconditional growth characteristics, but they are unable to explain the dependence on age and size simultaneously. ${ }^{8}$ This paper's empirical findings shed light on an important yet lesserknown aspect of firm dynamics. I show that intangible assets, when interacting with financial frictions, can generate substantial heterogeneity among entrants, as well as convergence inertia among young firms. Moreover, the share of intangible assets is an important factor in firm dynamics, in addition to age and size.

This paper contributes to the developing literature on intangible assets. ${ }^{9}$ I construct new measures of intangible assets by accumulating firms' selling, general, and administrative (SG\&A) expense as reported in the Compustat data. SG\&A expense is an appropriate proxy of intangible investment because it includes most of the expenditures firms use to accumulate intangible assets, such as employee training, marketing, research and development, and payments to strategy consultants. ${ }^{10}$ I contribute to this literature by documenting evidence that resources allocated to SG\&A expense have long-run impacts on firm performance and market value.

The rest of the paper is organized as follows. Section II describes the model and derives its testable implications. Section III describes the data and presents empirical findings. Section IV concludes.

\section{THE MODEL}

Time is discrete and the time horizon is infinite. A firm is born with zero assets and an investment project. The project requires a sunk setup cost $I_{0}$ and generates flow profit $F(k, a, z)$, where $k$ and $a$ are variable capital inputs and $z$ is an idiosyncratic revenue shock. I hereafter refer to $k$ as physical assets and $a$ as intangible assets, I make the following assumptions about the profit function and the shock.

Assumption 1: The function $F: \mathscr{K} \times \mathscr{A} \times \mathscr{Z} \rightarrow \mathscr{R}_{+}$is strictly increasing, strictly concave, and twice continuously differentiable in $k$ and $a$, and increasing in $z$. It satisfies $F(k, 0, z)=$ $F(0, a, z)=0$ and has decreasing returns to scale, that is, $\forall \boldsymbol{\imath}>0, f(\imath k, \imath a)<\imath f(k, a)$.

Assumption 2: The stochastic process of $z$ has bounded and finite support $\mathscr{Z}=\left[z^{1}, z^{2}, \ldots, z^{N}\right]$, $N \geq 2$. $z$ follows a common stationary and monotone (increasing) Markov transition function.

Decreasing returns to scale implies an optimal firm size. This property may result from limited managerial technology, as in Lucas (1978).

\footnotetext{
${ }^{7}$ Jovanovic (1982) has a model with learning and Hopenhayn (1992) has a model with persistent shocks to the production technology.

${ }^{8}$ See Cooley and Quadrini (2001) for a detailed discussion.

${ }^{9}$ See, among others, Atkeson and Kehoe (2005), McGrattan and Prescott (2000), and Laitner and Stolyarov (2003).

${ }^{10}$ For detailed discussions on SG\$A, see Lev (2001) and Lev and Radhakrishnan (2005). For recent papers that use SG\&A as a proxy for intangible investment, see Eisfeldt and Papanikolaou (Forthcoming) and Falato, Kadyrzhanova and Sim (2013).
} 
The firm can seek debt financing from outside investors, or debtholders. I define debt by its claim structure and control rights. In exchange for funds, the firm promises contingent payments and control rights. If the firm repudiates the contract, the debtholders can exercise their control rights and take over the firm. The debtholders and the firm have the same discount rate $r>0$.

The timing of actions and associated payoffs is as follows. At time zero, initial productivity $z_{0}$ is realized and observed publicly. The firm signs a long-term contract. A contract $c$ specifies funds for the setup cost $I_{0}$, delivered from the debtholders, and a triplet of functions $c:\left\{k_{t}, a_{t}, d_{t}\right\}_{t=1}^{\infty}$, which determines funds for assets $k_{t}$ and $a_{t}$ delivered at the end of period $t-1$, a dividend payment $d_{t}$ to the firm, and a debt payment to the debtholders delivered at the end of period $t .{ }^{11}$ Even though the dividend payment $d_{t}$ is made at the end of the period $t$, it is contracted in period $t$. This timing assumption simplifies the analysis considerably. ${ }^{12}$ The triplet $\left\{k_{t}, a_{t}, d_{t}\right\}_{t=1}^{\infty}$ implicitly defines a sequence of payments to the debtholders, who receive all cash flow net of dividends. The funds and payments in the contract are contingent on the history of shocks. The contingent debt repayment schedule can be viewed as a fixed payment schedule without prepayment penalties. Specifically, the contract can specify a minimum (possibly zero) fixed payment and allow for increased payment at the borrower's discretion. More generally, this specification is consistent with empirical debt contracts with covenants restricting firms' investment, dividend and financing policies.

Although debtholders behave competitively and have full commitment to the contract, the firm has limited liability and can choose to repudiate the contract. At the end of each period, the firm can divert $D\left(k_{t}, a_{t}\right)$ from the funds for $k_{t}$ and $a_{t}$. I refer to $D\left(k_{t}, a_{t}\right)$ as the repudiation value and will discuss its specification later. In case of a repudiation, the debtholders take control. Because debtholders cannot run a firm, perhaps because of the lack of skills, they commit no further funds and liquidate the business. If the firm does not repudiate the contract, it survives to the next period with probability $1-\varphi$. At the beginning of the next period, conditional on survival, $z_{t}$ is realized and production takes place. The revenues from production are used to make debt and dividend payment and to finance the new assets $k_{t+1}$ and $a_{t+1}$. The timing of events is illustrated in Figure 2.

Let $B_{c}$ denote the contract value to the debtholders from some contract $c$ and let $V_{c}$ denote the contract value to the firm. The value to debtholder satisfies the following recursion: ${ }^{13}$

$$
B_{c}=-R_{k} k^{\prime}-R_{a} a^{\prime}+\beta \mathbb{E}\left[F\left(k^{\prime}, a^{\prime}, z^{\prime}\right)-d^{\prime}+B_{c}^{\prime}\right],
$$

where the discount rate is $\beta=\frac{1-\varphi}{1+r}$ (recall the firm survives to the next period with probabil-

\footnotetext{
${ }^{11}$ It is important for the purpose of this model that physical and intangible assets can be specified separately in a contract. One natural extension is to assume that intangible assets are not contractible perhaps due to nonveriafiability of the value of intangible assets. The resulting constraints would be more restrictive.

${ }^{12}$ Following this assumption, the Bellman equation (11) does not depend on $d_{t}$ implicitly. Even though $d_{t}$ is determined before shock $z_{t}$ is realized, the structure of the problem (see Proposition 1) ensures that the optimal $d_{t}$ is never greater than the firm's revenue for any $z_{t}>0$ so the firm can always pay the contracted dividend if it does not default.

${ }^{13}$ I shall use letters without subscripts to denote current period values and with a prime to denote next period's value.
} 
Figure 2: Timing of Events

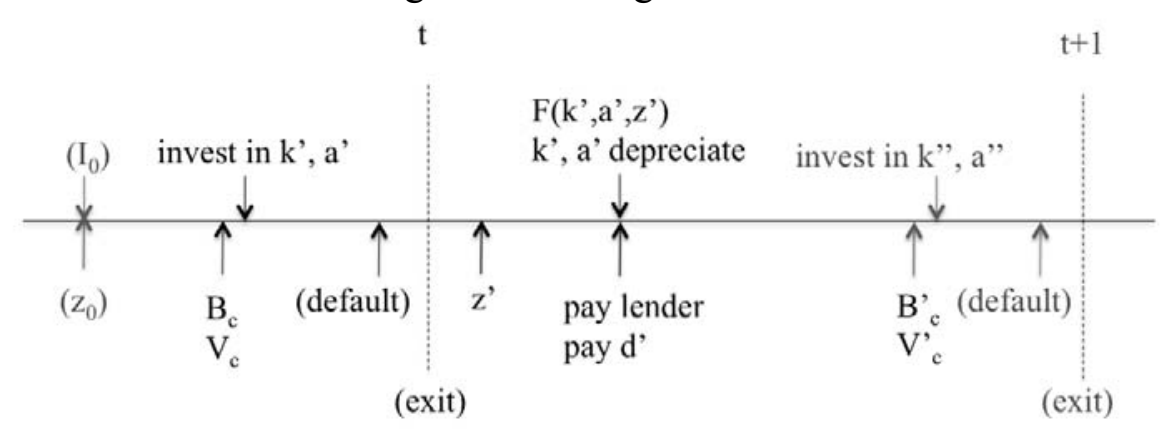

ity $1-\varphi)$. The flow payoff to the debtholders consists of the expected present value of debt repayment $\beta \mathbb{E}\left[F\left(k^{\prime}, a^{\prime}, z^{\prime}\right)-d^{\prime}\right]$, net of the cost of investment $R_{k} k^{\prime}+R_{a} a^{\prime}$. The cost of investment, $R_{j} \equiv 1-\beta\left(1-\delta_{j}\right)-\frac{\varphi}{1+r}, j=\{k, a\}$, can be interpreted as follows: For every unit of assets, the firm makes a dollar of investment at the end of the current period, which is a cost; conditional on survival, the assets' value in the next period after production and depreciation is $1-\delta_{j}$; with probability $\varphi$, the firm exits and the liquidation value is one.

The value to the firm can also be written in a recursive form:

$$
V_{c}=\beta\left(d^{\prime}+\mathbb{E} V_{c}^{\prime}\right)
$$

Let $h_{t}=\left\{z_{0}, z_{2}, \ldots, z_{t}\right\}$ denote the history of shocks up to date $t$ and let $\mathscr{C}\left(h_{t-1}\right)$ denote the set of contracts contingent on history $h_{t-1}$. A contract is feasible if the dividend payment is nonnegative

$$
d^{\prime} \geq 0
$$

for any history $h_{t-1}$ and $(k, a, d)=\mathscr{C}\left(h_{t-1}\right)$. This condition says that the firm is financially constrained and has no additional source of funds. ${ }^{14}$

For a contract to be enforceable, the firm should not have an incentive to repudiate. In case of a repudiation, the firm diverts $\eta_{k}$, a fraction of the value of physical assets, and $\eta_{a}$, a fraction of the value of intangible assets. The repudiation value to the firm is

$$
D\left(k^{\prime}, a^{\prime}\right)=\eta_{k} k^{\prime}+\eta_{a} a^{\prime}
$$

Diversion generates private benefits to the firm, which may result from various limitations of the enforceability of the contract, for example, the inalienability of assets from the owner of the firm, costly verification of wrongdoing, or imperfectly defined property rights. The severity of limited enforceability is captured by $\eta_{k}$ and $\eta_{a}$. When $\eta_{k}$ and $\eta_{a}$ are large, the value of repudiating a contract is high. I assume $0 \leq \eta_{k}<\eta_{a} \leq 1$, so the repudiation value to

\footnotetext{
${ }^{14}$ This assumption can be relaxed by allowing firms to obtain additional funds from equity holders at a cost. However, some sort of constraints on additional funds is crucial. Without it, financial frictions of the long-term contract become irrelevant because the first best could be achieved by having the firm pay a lump sum transfer to debtholders at the beginning of the contract, which would be forfeited if the firm defaults.
} 
the firm is higher for intangible assets than physical assets. A perfect financial market requires $\eta_{k}=\eta_{a}=0$.

The firm does not have incentive to repudiate if $D\left(k^{\prime}, a^{\prime}\right)$ is less than the value of continued production; thus, the enforcement constraint is given by

$$
\beta\left(d^{\prime}+\mathbb{E} V_{c}^{\prime}\right) \geq D\left(k^{\prime}, a^{\prime}\right),
$$

for any history of the shocks.

The maximum debt that can be credibly repaid from time zero can be derived as follows. Competitive lending implies that the initial debt value is equal to the setup cost $B\left(V_{0}, z_{0}\right)=I_{0}$. The contracting problem at time zero is to find a feasible and enforceable contract that gives the highest value to the firm consistent with the debtholders breaking even, so the initial value to the firm is $V_{0}=\sup \left\{V: B\left(V, z_{0}\right)=I_{0}\right\}$ and the initial value to debtholders is

$$
B\left(V_{0}, z_{0}\right)=\sup _{c \in \mathscr{C}\left(z_{0}\right)}\left\{B_{c}\left(z_{0}\right) \mid V_{c}\left(z_{0}\right)=V_{0}\right\}
$$

An optimal contract cannot be Pareto-dominated after any realization of the shocks. Otherwise, it would be possible to make a Pareto improvement by replacing the part of the contract that was dominated and relaxing all previous enforcement constraints. It follows that the set of optimal contracts can be characterized by a Pareto frontier defined for any history $h_{t-1}$ and for any feasible value to the firm $V$ that maximizes the debt value of the contract. ${ }^{15}$

$$
B(V, z)=\sup _{c \in \mathscr{C}\left(h_{t-1}\right)}\left\{B_{c}\left(h_{t-1}\right) \mid V_{c}\left(h_{t-1}\right)=V\right\} .
$$

Following (5) and (6), $B($.$) depends on the history h_{t-1}$ only through $z_{t-1}$, because the constraint set is stationary and the information set is identical in these two equations. It follows that the value to the debtholders on the Pareto frontier can be written in a recursive form:

$$
B(V, z)=\max _{\substack{k^{\prime}, a^{\prime}, d^{\prime} \\
V\left(z^{\prime}\right), \forall z^{\prime} \in\left[z^{1}, \ldots, z^{N}\right]}}\left\{\begin{array}{c}
-R_{k} k^{\prime}-R_{a} a^{\prime} \\
+\beta \mathbb{E}\left[F\left(k^{\prime}, a^{\prime}, z^{\prime}\right)-d^{\prime}+B\left(V\left(z^{\prime}\right), z^{\prime}\right)\right]
\end{array}\right\},
$$

subject to

$$
\begin{gathered}
d^{\prime} \geq 0, \\
\beta\left(d^{\prime}+\mathbb{E} V\left(z^{\prime}\right)\right) \geq D\left(k^{\prime}, a^{\prime}\right), \\
\beta\left(d^{\prime}+\mathbb{E} V\left(z^{\prime}\right)\right)=V .
\end{gathered}
$$

The first two constraints ensure the feasibility and enforceability of the contract. The last constraint ensures the dynamic consistency: The current value to the firm is equal to the discounted expected value of dividend payment plus the continuation value. ${ }^{16}$

\footnotetext{
${ }^{15} V$ is feasible in the sense that there exists $c \in \mathscr{C}\left(h_{t-1}\right)$ that yields this value.

${ }^{16}$ Assuming debtholders' full commitment to the contract simplifies the problem considerably. Without it, the debtholders' participation constraint would have to be imposed for every period: $B\left(V_{t-1}, z_{t-1}\right) \geq 0$ and the problem could not be transformed into a standard dynamic programming problem. In principle, $B\left(V_{t-1}, z_{t-1}\right) \geq 0$ is satisfied if the shock $z$ never gets too low. To ensure that this assumption does not affect the solution of the problem, I check in the numerical solution that $B\left(V_{t-1}, z_{t-1}\right) \geq 0$ for all parameterizations used in the paper.
} 
In this problem, $V$ can be viewed as a state variable. Given values $V$ and $z$, the optimal contract specifies funds for assets $k^{\prime}$ and $a^{\prime}$ which takes place at the end of the current period and a dividend payment $d^{\prime}$ which takes place after production in the next period. The contract also specifies a continuation value $V\left(z^{\prime}\right)$ contingent on the shock $z^{\prime}, \forall z^{\prime} \in\left\{z^{1}, \ldots, z^{N}\right\}$. The law of motion for the state variable $V$ is simple. The future value of $V$ equals the continuation value currently promised by the contract depending on the realization of the shock.

So far the problem is characterized by maximizing the debt value $B(V, z)$ given $V$. Let $W(V, z) \equiv$ $B(V, z)+V$ denote the total surplus of the contract. It is easy to see that the optimal contract also maximizes $W(V, z)$ given $V$. Using (10), the enforcement constraint (9) simplifies to

$$
V \geq D\left(k^{\prime}, a^{\prime}\right)
$$

Using (8), (10) simplifies to

$$
V \geq \beta \mathbb{E} V\left(z^{\prime}\right)
$$

An equivalent dynamic programming problem to (7) is given by ${ }^{17}$

$$
W(V, z)=\max _{\substack{k^{\prime}, a^{\prime} \\
V\left(z^{\prime}\right) \geq 0, \forall z^{\prime} \in\left[z^{1}, \ldots, z^{N}\right]}}\left\{\begin{array}{c}
-R_{k} k^{\prime}-R_{a} a^{\prime} \\
+\beta \mathbb{E}_{z^{\prime} \mid z}\left[F\left(k^{\prime}, a^{\prime}, z^{\prime}\right)+W\left(V\left(z^{\prime}\right), z^{\prime}\right)\right]
\end{array}\right\}
$$

subject to

$$
\begin{gathered}
V \geq D\left(k^{\prime}, a^{\prime}\right) . \\
V \geq \beta \mathbb{E}_{z^{\prime} \mid z} V\left(z^{\prime}\right) .
\end{gathered}
$$

where $R_{j} \equiv 1-\beta\left(1-\delta_{k}\right)-\frac{\varphi}{1+r}, j=\{k, a\}$ and $D\left(k^{\prime}, a^{\prime}\right)=\eta_{k} k^{\prime}+\eta_{a} a^{\prime}$. The continuation value $V\left(z^{\prime}\right)$ must be supported by a feasible continuation contract. Any nonnegative continuation value is feasible because it can be obtained by giving the firm a transfer equal to $V\left(z^{\prime}\right)$ and committing to zero asset in the future. Any $V\left(z^{\prime}\right)<0$ is infeasible since it is inconsistent with the nonnegative dividend constraint. $V\left(z^{\prime}\right) \geq 0$ is the domain restriction indicated in problem (11). Standard dynamic programming results show that there is a unique solution to the function $W($.$) .$

\section{A Properties of an Optimal Contract}

\section{Contract Value and the Efficient Frontier}

In problem (11), current value $V$ sets a limit on assets $k^{\prime}$ and $a^{\prime}$ by constraint (12). $V$ sets a limit on the continuation value $V\left(z^{\prime}\right)$ by constraint (13). As a result, the choice of $k^{\prime}$ and $a^{\prime}$ can be solved in a static maximization problem separate from the dynamic choice of $V\left(z^{\prime}\right)$. The static problem is to maximize the indirect profit function

$$
\pi^{*}(V, z)=\max _{k^{\prime}, a^{\prime}}\left\{-R_{k} k^{\prime}-R_{k} a^{\prime}+\beta \mathbb{E}_{z^{\prime} \mid z} F\left(k^{\prime}, a^{\prime}, z^{\prime}\right)\right\}
$$

\footnotetext{
${ }^{17}$ The alternative formulation eliminates dividend payment from the problem and simplifies analysis.
} 
subject to (12). The solution to this problem is simple: A value $V$ exists such that constraint (12) does not bind. Let $\left(k^{*}(z), a^{*}(z)\right)=\arg \max _{k^{\prime}, a^{\prime}}\left\{-R_{k} k^{\prime}-R_{a} a^{\prime}+\beta \mathbb{E} F\left(k^{\prime}, a^{\prime}, z^{\prime}\right)\right\}$ be the unconstrained level of assets and define $V^{*}(z)=D\left(k^{*}(z), a^{*}(z)\right) . V^{*}(z)$ is the smallest value for the firm that is compatible with unconstrained expected profit maximization. If $V<V^{*}(z)$, the unconstrained assets level cannot be achieved and $k^{\prime}$ and $a^{\prime}$ are picked so that $V=D\left(k^{\prime}, a^{\prime}\right)$. If $V \geq V^{*}(z)$, the policy is identical to one obtained in an unconstrained problem; however, this does not mean that the firm has grown out of constraint indefinitely. Stronger conditions are necessary to ensure that the enforcement constraint will not bind in the future. To see this, let $V^{n}(z)$ denote the minimal value needed so that the enforcement constraint does not bind for at least $n \geq 1$ periods. Let $V^{0}(z)=0$ and define

$$
V^{n}(z)=\max \left\{V^{*}(z), \beta \mathbb{E}_{z^{\prime} \mid z} V^{n-1}\left(z^{\prime}\right)\right\} .
$$

Assume that for every $z \in \mathscr{Z}$, a constant $M<0$ exists such that $V^{*}(z) \leq M$. Since $V^{n}(z)$ is an increasing sequence, this assumption guarantees that the sequence is uniformly bounded and has a limit. Denote this limit by $\tilde{V}(z) \equiv \lim _{n \rightarrow \infty} V^{n}(z)$. Applying Lebesgue's dominated convergence theorem to (15) implies that $\tilde{V}(z)$ satisfies the following dynamic programming equation:

$$
\tilde{V}(z)=\max \left\{V^{*}(z), \beta \mathbb{E}_{z^{\prime} \mid z} \tilde{V}\left(z^{\prime}\right)\right\} .
$$

Blackwell's sufficient conditions can be verified so the solution $\tilde{V}(z)$ is unique. $\tilde{V}(z)$ defines the minimum value for the firm that is consistent with unconstrained profit maximization. Once $\tilde{V}(z)$ is reached, financial constraint no long matters. I henceforth call $\tilde{V}(z)$ the efficient frontier to capture the result that once it is reached, the total surplus of the contract cannot be improved by manipulating the debt level. This is formally stated in Lemma 1.

Lemma 1 (i) $W(V, z)$ is weakly increasing in $V$; (ii) Let $\tilde{W}(z)$ be the solution to

$$
\tilde{W}(z)=\mathbb{E}_{z^{\prime} \mid z}\left[\pi^{*}(z)+\beta \tilde{W}\left(z^{\prime}\right)\right] .
$$

For all $V \geq \tilde{V}(z), W(V, z)$ is constant and equal to $\tilde{W}(z) ;$ (iii) For all $V<\tilde{V}(z), W(V, z)<$ $\tilde{W}(z)$.

Proof. See Appendix.

The next two lemmas discuss concavity and monotonicity of the total surplus function $W$.

Lemma $2 W(V, s)$ is strictly concave in $V$ when $V<\tilde{V}(z)$.

Proof. See Appendix.

Lemma $3 W(V, z)$ is strictly increasing in $V$ when $V<\tilde{V}(z)$. 
Proof. See Appendix.

A direct implication of the strict monotonicity of $W($.) in $V$ for all $V<\tilde{V}(z)$ is that the optimal policy requires no dividends be distributed before firm's value reaches the efficient frontier and all earnings be allocated as debt repayment. The intuition is simple. The firm's input is constrained by its current value by the enforcement constraint (12). Postponing dividend payment increases the continuation firm value and relaxes future constraints. Formally,

Proposition 1 If $V<\beta \mathbb{E}_{z^{\prime} \mid z} \tilde{V}\left(z^{\prime}\right)$, the optimal policy requires no dividends be distributed.

\section{B Model Implications}

This section considers model implications for firm dynamics and Tobin's q. When possible, I derive analytical implications of the model. I also complement the analysis with numerical results. The numerical model is solved by value function iteration and simulated by drawing a large number of independent sample paths for firm shocks. Numerical solution method is discussed in detail in the appendix.

\section{Age Effects}

Firm Size Throughout this subsection, I identify firm size through firm profit $\pi$ as defined in (14). I refer a firm as mature when when $V \geq \tilde{V}(z)$. Albuquerque and Hopenhayn (2004) show that conditional on the revenue state of the firm, firm size grows monotonically over time. I now show that similar argument goes through in my set-up. ${ }^{18}$

Proposition 2 Conditional on the revenue state of the firm $z$, firm size increases with age before the firm matures.

Proof. Take any $V<\beta \mathbb{E}_{z^{\prime} \mid z} \tilde{V}\left(z^{\prime}\right)$ so the constraint (13) binds for problem (11). An interior solution $V\left(z^{\prime}\right)$ is chosen so that the first derivative $W_{V}$ is equalized across all $z$. By the envelope theorem,

$$
W_{V}(V, z)=\beta \pi_{V}(V, z)+W_{V}\left(V\left(z^{\prime}\right), z^{\prime}\right) .
$$

This implies that $W_{V}$ is strictly decreasing over time conditional on $z$, when $\pi_{V}>0$. By the strict concavity of $W(V, z)$, decreasing $W_{V}$ implies increasing $V$. Recall from (14) that $\pi_{V}>$ 0 implies the borrowing constraint binds, in which case $k^{\prime}$ and $\alpha^{\prime}$ are chose such that $V=$ $D\left(k^{\prime}, a^{\prime}\right)$. It is easy to see that increasing profit follows directly from increasing $V$.

\footnotetext{
${ }^{18}$ Firm size in the Albuquerque and Hopenhayn (2004) model refers to working capital, which is a convenient metrics because their model implies a simple monotonic relationship between working capital and equity value. In a multiple assets setting, profit is a more preferrable metrics because it is not affected by the substitution effect between different assets.
} 
Figure 3: Tobin's Q and Intangible Adjusted Q: Data
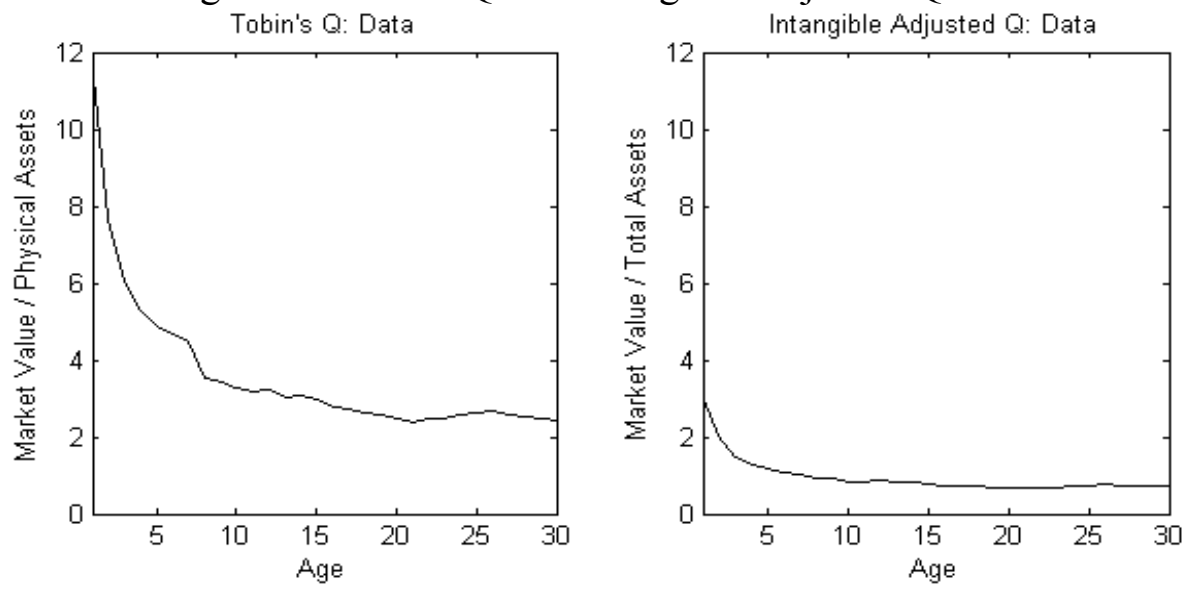

Tobin's $\boldsymbol{q}$ The result that conditional on $z$, the value of $W$ and $V$ are increasing sequences also has important consequence on Tobin's q. Conventionally, Tobin's q is calculated as ratio of the market value to the replacement value of a firm, with the latter measured by the book value of physical assets. As shown in the left panel of Figure 3, this ratio is usually greater than one. It is higher for younger firms. It falls and levels off among older firms. ${ }^{19}$ The change of Tobin's q over the life cycle is quite pronounced. Tobin's q is on average around 12 for entrant firms but falls to around 2 for firms 15 years or older. Similar age pattern holds if the replacement value is measured by the book value of total assets (i.e. the sum of physical and intangible assets). The intangible adjusted $\mathrm{q}$ is around 3 for entrant firms but fall to around 1 among older firms. Although Tobin's q is widely use as an indicator for investment and market valuation, the age dynamics of Tobin's q has largely eluded the literature on firm dynamics. I now address this evidence under my framework.

Let $\mathbb{W}_{t}$ denote the market value, which is given by the sum of the expected discounted stream of earnings net of investment expenditure on physical and intangible assets $i_{k}$ and $i_{a}$, plus liquidation value upon exit and the setup cost. Investment expenditure satisfies the following assets accumulation equations:

$$
i_{k, t}=k_{t+1}-\left(1-\delta_{k}\right) k_{t}
$$

and

$$
i_{a, t}=a_{t+1}-\left(1-\delta_{a}\right) a_{t},
$$

It is convenient to express $\mathbb{W}_{t}$ through (16) and (17) so it does not depend on investment explicitly:

$$
\mathbb{W}_{t}=\mathbb{E}_{t} \sum_{s=1}^{\infty} \beta^{s-1}\left(\begin{array}{c}
\frac{\varphi}{1+r} k_{t+s}+\frac{\varphi}{1+r} a_{t+s}+\beta F\left(k_{t+s}, a_{t+s}, z_{t+s}\right) \\
-\beta\left[k_{t+s+1}-\left(1-\delta_{k}\right) k_{t+s}\right]-\beta\left[a_{t+s+1}-\left(1-\delta_{a}\right) a_{t+s}\right]
\end{array}\right)+I_{0} .
$$

\footnotetext{
${ }^{19}$ The sample of firms is from the annual Standard and Poor's Compustat industrial file and the Center for Research in Security Prices (CRSP) monthly stock file. See Section III for detailed descriptions of the data, variable measurement and results.
} 
Following the convention, Tobin's $q$ is defined as the ratio of the market value of the firm to the replacement cost of physical assets. ${ }^{20}$ Omitting the time subscript, this gives

$$
q^{\text {Tobin }} \equiv \frac{\mathbb{W}}{I_{0}+k^{\prime}}
$$

In my set-up, the firm's market value and investment opportunity set include both physical and intangible assets. It is natural to extend this definition to include the value of intangible assets. Define the intangible adjusted $q$ by

$$
q^{a d j} \equiv \frac{\mathbb{W}}{I_{0}+k^{\prime}+a^{\prime}}
$$

The next result relates the market value of the firm to $W$.

Lemma 4 The market value of a firm captures the expected surplus value of its financial contract and the book value of its physical and intangible assets:

$$
\mathbb{W}=W+k^{\prime}+a^{\prime}+I_{0}
$$

Proof. See Appendix.

It follows immediately that

$$
q^{\text {Tobin }}=\frac{W+a^{\prime}}{I_{0}+k^{\prime}}+1
$$

and

$$
q^{a d j}=\frac{W}{I_{0}+k^{\prime}+a^{\prime}}+1,
$$

It is easy to see from (21) that asset accumulation affects the dynamics of Tobin's q both directly (through the replacement value of assets) and indirectly (through the market value). To motivate the analysis, consider a simplified case with only one type of assets (e.g. $k$ ). Recall that when the firm is in a set where $V<\beta \mathbb{E}_{z^{\prime} \mid z} \tilde{V}\left(z^{\prime}\right)$, equity value is increasing and the borrowing constraint is binding. Substituting $V=D=\eta_{k} k^{\prime}$ gives $q^{\text {Tobin }}=\eta_{k} W(V, z) /\left(\eta_{k} I_{0}+V\right)+1$. By the strictly monotonicity and convexity of $W(V, z), q^{\text {Tobin }}$ is decreasing in $V$ condition on the revenue state. Once a region is reached where $V=\tilde{V}(z)$, age will have no further growth effects. Analytical results are difficult to derived with two types of assets. But simulation results are presented in Figure 4. The graph shows that Tobin's q decreases with age before it levels off. Similar result holds for intangible adjusted $\mathrm{q}$ as well. This age pattern has a simple intuition. Before the firm reaches the efficient frontier $\tilde{V}(z)$, assets are constrained to be small; however, the market value is less affected because it is a forward-looking variable that captures the assets' revenue potential. In summary,

\footnotetext{
${ }^{20}$ I choose to include the sunk cost $I_{0}$ in the firm's fixed assets so that the definition of Tobin's q is comparable to the one in Albuquerque and Hopenhayn (2004). In real life, the sunk cost $I_{0}$ may or may not be recognized as a firm's fixed assets.
} 
Figure 4: Tobin's Q and Intangible Adjusted Q: Simulated Model
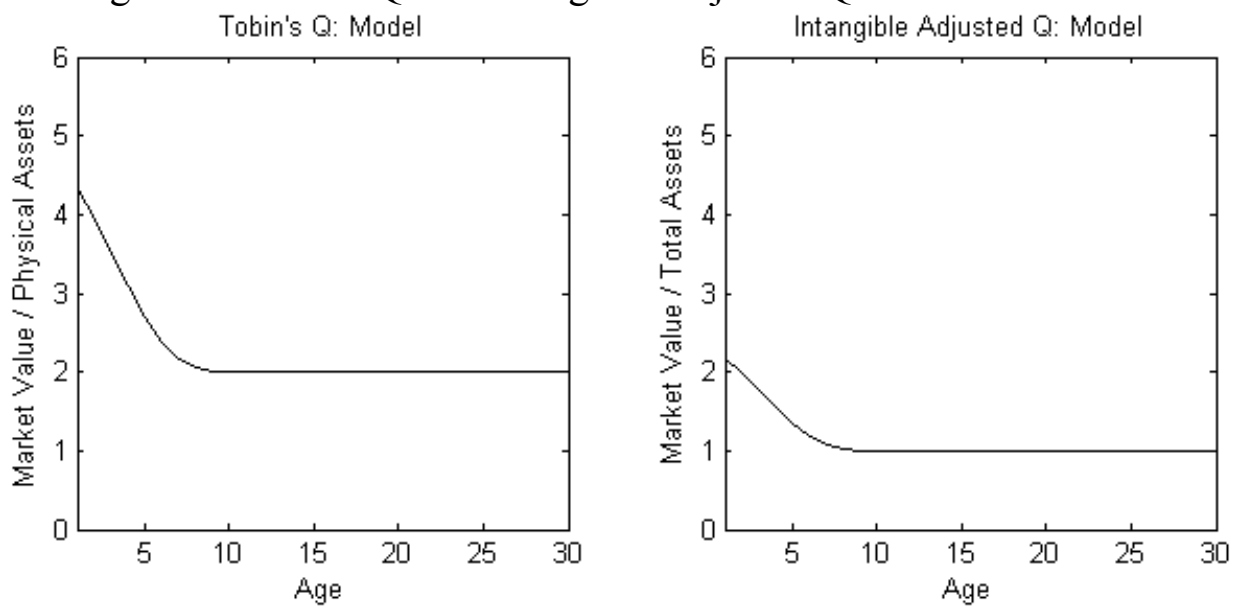

Proposition 3 Conditional on the revenue state of the firm, Tobin's q decreases with age before the firm reaches its optimal size.

Contrast this result with one from a model without asset accumulation. When $k$ is modeled as working capital. Book the book value consists of only $I_{0}$ because working capital depreciates completely every period. Thus $q^{\text {Tobin }}=W(V, z) / I_{0}+1$. When the firm is in a set where $V<\beta \mathbb{E}_{z^{\prime} \mid z} \tilde{V}\left(z^{\prime}\right)$, the value $W$ is increasing with age. It follows that Tobin's q is also increasing with age. Thus, in my model, limited enforcement and capital accumulation both contribute to the negative relationship between firm Tobin's q and age before a firm matures.

Figure 4 presents simulation results of Tobin's q and intangible $q$ under the full model. The model predicts that the average Tobin's q is high among young firms. It then decreases with age and levels off among older firms. Similar pattern holds for intangible adjusted q.

Intangible Intensity In the previous subsections, I show that financial friction constrains the firm from operating on the efficient scale. I now turn the focus to another channel of inefficiency: the debt contract distorts investment and leads to inefficiency allocation between physical and intangible scale. Intuitively, a firm invests relatively more intensively in $k^{\prime}$ when it is constrained because the enforcement constrained is more restrictive in intangible assets.

Proposition 4 Conditional on the revenue state of the firm, the share of intangible assets increases with age before the firm reaches its optimal size.

Proof. See Appendix.

In the model, the age variation in the share of intangible assets reflects financial frictions of a firm being relaxed over time whereas the cross-sectional variation reflects the severity of financial constraints across firms due to heterogeneous production technologies. ${ }^{21}$

\footnotetext{
${ }^{21}$ Quantitatively, the age variation in the share of intangible share is small in the model and in the data.
} 


\section{Asset Tangibility Effects}

As Figure 1 illustrates, firms with different asset tangibility experience very different size and Tobin's q dynamics. Firms with a higher share of intangible assets are smaller with a higher Tobin's $q$ at their early stage of life. In this subsection, I discuss the implications of asset tangibility for firm size and Tobin's q under the optimal financial contract.

To introduce heterogeneity in asset tangibility, I assume that firms differ in their production technology with respect to physical and intangible assets. I use a Cobb-Douglas profit function $F(k, a, \gamma)=e^{z}\left(k^{\gamma} a^{1-\gamma}\right)^{\theta}$, where $\gamma$ is a firm-specific production parameter drawn from a common distribution when a firm is started. ${ }^{22}$ With this parameterization, it is easy to check that the share of physical assets is increasing in $\gamma$ among unconstrained firms. ${ }^{23}$

Since detailed implications are very difficult to derive for the full model, I first provide analytical results under two simplifying assumptions: (i) Firms have identical and deterministic shock $z$; (ii) The repudiation value of physical assets is zero, so $D\left(k^{\prime}, a^{\prime}\right)=\eta_{a} a^{\prime}$. I then present numerical results for the full model at the end of this subsection.

Under the simplifying assumptions, firm $i$ 's problem is a special case of (11). All previous results go through, except that the value and policy functions will depend on the firm specific production technology parameter $\gamma$. The efficient frontier also depends on $\gamma$. To see this, note that with deterministic $z$, the efficient frontier equals the smallest $V$ that is compatible with unconstrained expected profit maximization. In particular, let $V^{*}(\gamma)=D\left(k^{*}(\gamma), a^{*}(\gamma)\right)=$ $\eta_{a} a^{*}(\gamma)$. Following Proposition $1, d=0$ before the efficient frontier is reached; thus, $V=\beta V^{\prime}$, implying $V$ is growing. If the enforcement constraint does not bind in the current period, it will never bind in the future; therefore, $\tilde{V}(\gamma)=V^{*}(\gamma)$. The enforcement constraint becomes $\tilde{V}(\gamma)=\eta_{a} a^{*}(\gamma)$. It is easy to check that $a^{*}(\gamma)$ is decreasing in $\gamma$ so $\tilde{V}(\gamma)$ is decreasing in $\gamma$. In other words, a firm with a production technology that is more intensive in intangible assets has a higher efficient frontier.

The next result discusses the monotonicity of entrant size in the share of intangible assets.

Proposition 5 Conditional on the revenue state $z_{0}$ of the firm, entrant firms with a higher share of intangible assets have lower equity value $\left(V_{0}\right)$ and smaller asset size ( $k_{0}$ and $\left.a_{0}\right)$.

\section{Proof. See Appendix.}

This result has a simple intuition. Firms with a higher share of intangible assets face more restrictive constraints; consequently, their initial size is smaller.

Growth in intangible assets is also related to the share of intangible assets. Following $V=\eta_{a} a^{\prime}$ and zero dividend, $\eta_{a} a^{\prime}=V=\beta V^{\prime}=\beta \eta_{a} a^{\prime \prime}$, so intangible assets grow at rate $1 / \beta-1$ before

\footnotetext{
${ }^{22} \mathrm{An}$ alternative way is to introduce heterogeneous costs of investment. For example, the costs of investment in $k$ relative to $a$ is firm-specific: $R_{k, i} / R_{a, i}=C_{i}$ for some constant $C_{i}$.

${ }^{23}$ For unconstrained firms, $\gamma$ and $\tau$ satisfy the following relationship: $\frac{1-\beta\left(1-\delta_{k}\right)}{1-\beta\left(1-\delta_{a}\right)}=\left(\frac{1}{\tau}-1\right) \frac{\gamma}{1-\gamma}$.
} 
the firm reaches the efficient frontier. The growth rate is zero afterwards. Given the initial size premium and the negative relationship between $\gamma$ and $\tilde{V}(\gamma)$, firms with low $\gamma$-implying a technology more intensive in intangible assets - take a longer time to mature.

Proposition 6 Conditional on the revenue state $z_{0}$ of the firm, entrant firms with a higher share of intangible assets have higher Tobin's $q$.

In the last subsection, I establish the general result that Tobin's q decreases with age while the firm is in a set where $V<\tilde{V}(z)$. Once a region is reached where $V=\tilde{V}(z)$, age will have no further effect on Tobin's q. Conditional on the revenue state $z$ of the firm, $V$ and $W$ will be identical among all matured firms. Following (21), Tobin's q will be determined by the relative size of physical and intangible assets, which are determined by the firm's technology parameter $\gamma$. It follows immediately that a firm with low $\gamma$ have a high share of intangible assets and high Tobin's q. This result combined with the monotonicity of Tobin's q in age implies that:

Corollary 1 Conditional on the revenue state and age of the firm, firms with a higher share of intangible assets have higher Tobin's q.

The next result focuses on firm growth.

Proposition 7 Among young age categories, firms with a higher share of intangible assets on average have higher growth rate in firm value $(V)$ and intangible assets $(a)$.

This result is a reflection of financial constraint being relaxed with age. Among young age categories, firms with lower $\gamma$ are more likely to be constrained. The share of intangible assets predicts the constrained status and in turn predicts firm growth and size. As age increases, more firms become unconstrained and the correlation between the share of intangible assets and growth diminishes. With deterministic $z$, the convergence in growth rate is exact since all firms have zero growth eventually. With stochastic $z$, the growth rate of an unconstrained firm depends on the realization of the shock. Conditional on $z$, growth converges in expectation.

Figure 5 summarizes simulation results of the full model. The figure plots the average firm size, growth, Tobin's q and intangible adjusted q for three groups of firms with high, median, and low shares of intangible assets. The model predicts that firms with a high share of intangible assets start with a smaller size and higher growth rate. The size and growth rate of the three groups converges. Firms with a higher share of intangible assets also have higher Tobin's q and intangible adjusted q. These predictions are qualitatively in line with empirical evidence presented in Section I and III.

As a final note to the discussion of model implications, my model is clearly not the first to generate implications for firm size and growth dynamics that are qualitatively in line with empirical evidence. Notable examples in the literature are Jovanovic (1982) and Hopenhayn (1992). The 
Figure 5: Intangible Asset, Firm Dynamics and Q: Simulated Model
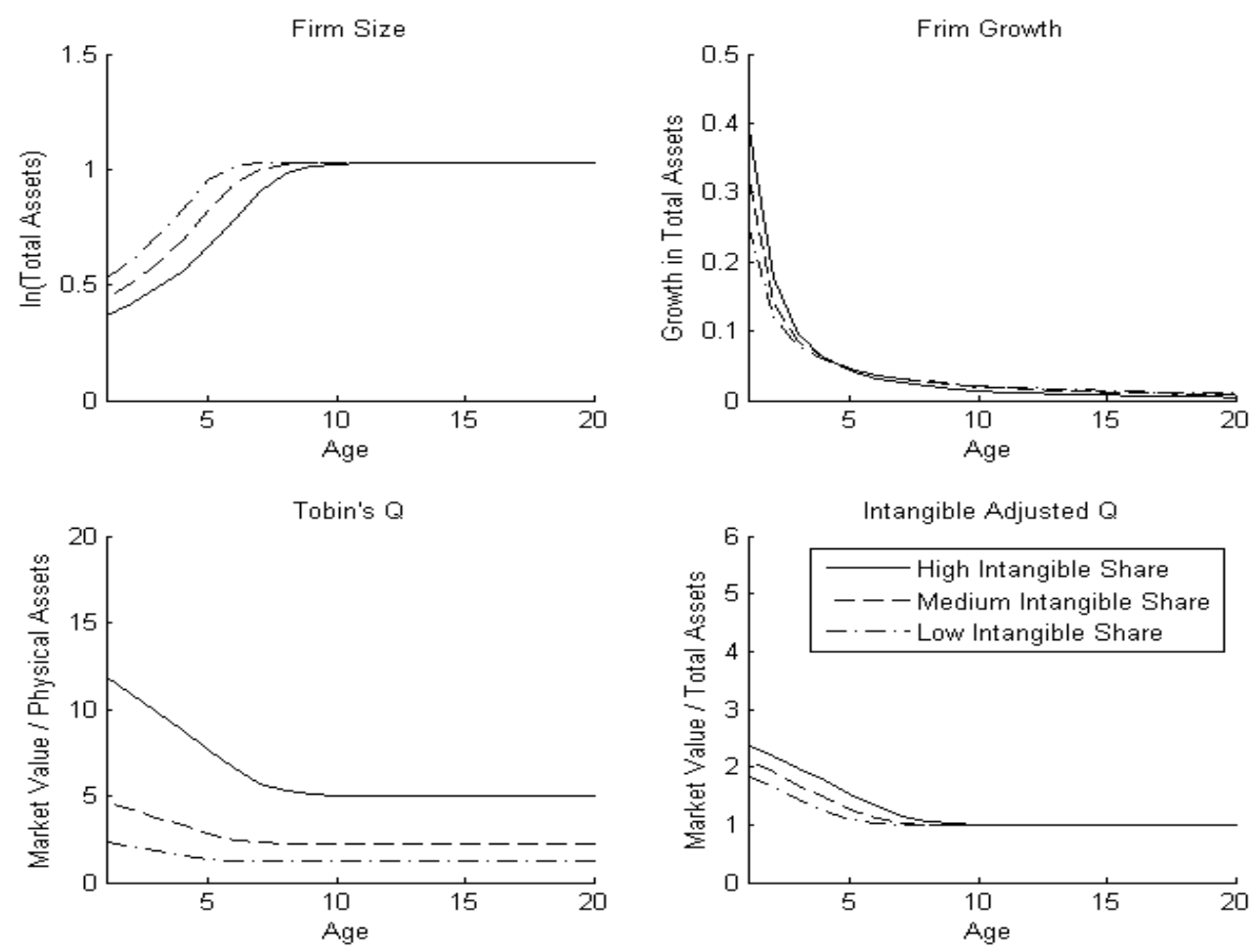

main difference of my approach is that it imposes much less structure on the stochastic process of the shock. Different from Albuquerque and Hopenhayn (2004) and Cooley and Quadrini (2001), my model generates a nontrivial role for the accumulation of heterogeneous assets in explaining Tobin's q dynamics. This provides a mapping from the nonobservable financial friction to readily observed variables on assets and investment. It also leads to a new set of testable implications which I explore in the next section.

\section{EMPIRICAL RESULTS}

I use data on U.S. public firms to derive key empirical results, which are consistent with the implications of my model.

\section{A Data}

The sample of firms is from the annual Standard and Poor's Compustat industrial file and the Center for Research in Security Prices (CRSP) monthly stock file. The sample period is 1979 to 2009. I select the sample by first deleting any firm-year observations for which the book value of total assets (item AT), physical assets (i.e., gross property, plant, and equipment, item PPEGT), employment (item EMP), or sales (item SALE) is either zero or negative. Following 
the literature, I remove firm-year observations if large discontinuities in total assets or assets stock exist because these discontinuities are likely to be caused by mergers and acquisitions. Firms with primary standard industrial classifications between 4900 and 4999 or between 6000 and 6999 are omitted because the theory is unlikely to be applicable to regulated or financial firms. I deflate all series by the GDP deflator from the U.S. Bureau of Economic Analysis.

\section{Measuring Assets}

Compustat reports the book value of a firm's gross property, plant, and equipment (item PPEGT); however, firms may have an incentive to overreport because of favorable tax treatments on depreciation. To alleviate this problem, I impute physical assets from physical investment expenditure because investment is harder to misreport and potentially more reliable. I calculate implied depreciation rate for every firm using

$$
\delta_{k, i}=\mathbb{E}\left[\frac{i_{i t-1}}{\hat{k}_{i t-1}}-\frac{\hat{k}_{i t}-\hat{k}_{i t-1}}{\hat{k}_{i t}}\right],
$$

where $\hat{k}_{i t}$ is the reported book value of physical assets (item PPEGT) and $i_{i t}$ is investment expenditure (item CAPX) minus the sale of property, plant, and equipment (item SPPE). I eliminate firms with $\delta_{k, i}<0$ or $\delta_{k, i}>1$. For the rest of the sample, I impute physical assets with a perpetual inventory equation and set the initial stock to the first observation of physical assets (item PPEGT) for each firm.

$$
\begin{aligned}
k_{i t} & =\left(1-\delta_{k, i}\right) k_{i t-1}+i_{i t-1}, \\
\text { with } k_{i 0} & =\hat{k}_{i 0} .
\end{aligned}
$$

One way to check the consistency between the data on investment flow and the stock of physical assets is to examine the implied depreciation rate in (22). I group the sample of firms with $0 \leq \delta_{k, i} \leq 1$ into 17 industries using the Fama and French (1997) classification and calculate the mean of $\delta_{k, i}$ by industry. As reported in Table 1, the depreciation rate ranges from 0.056 for automobile industry to 0.085 for the oil industry. This range is consistent with the literature.

In contrast to property, plant, and equipment, some assets are not physical by nature. Common examples of intangible assets are brand name, managerial skills and firm-specific technologies. The challenge of measuring intangible assets is well recognized. Under the U.S. generally accepted accounting principles (GAAP), internally generated intangible assets are not reported. Estimations on firm-level intangible assets are scarce. ${ }^{24}$ To bridge this gap, I extend the approach in Corrado, Hulten and Sichel (2006), which imputes aggregate intangible assets using investment data, to the firm level. Intangible investment is measured by expenditure on Selling, General, and Administrative (SG\&A). The GAAP defines the Selling, General, and Administrative expense as all commercial expenses of operation, such as expenses not directly related

\footnotetext{
${ }^{24}$ One exception is Eisfeldt and Papanikolaou (Forthcoming), whose similarly impute organization capital for U.S. public firms. They find that firms with more organization capital have higher stock returns than their industry peers, suggesting that these firms are more risky.
} 
to production, incurred in the regular course of business pertaining to the securing of operating income. Companies usually explicitly discuss the level and changes of SG\&A in the managerial discussion and analysis (MD\&A) section of their 10-K financial reports. In general, SG\&A includes most of the expenditure related to business intangible outlays and knowledge input, such as advertising and marketing expense, (company-sponsored) research and development, employee training, payment to systems and strategy consultants, and the cost of setting up and maintaining internet-based supply and distribution channels. As a consequence, SG\&A expenditure usually has a long-term impact on firm performance because it supports activities that improve employee incentive, operation efficiency, and customer loyalty (Lev (2001) and Lev and Radhakrishnan (2005)). I construct the stock of firm $i$ 's intangible assets $a_{i t}$ using a perpetual inventory equation

$$
a_{i t}=\left(1-\delta_{a}\right) a_{i t-1}+S G A_{i t-1},
$$

where $S G A_{i t}$ is the SG\&A expenditure (Compustat annual item XSGA). Two additional elements are needed to implement (24): initial intangible assets $a_{i 0}$ and depreciation rate $\delta_{a}$. I set the initial stock of intangible assets to the first reported value of intangible assets (item INTAN). The model provides some guidance on the choice of $\delta_{a}$. It suggests that if physical assets and intangible assets have different depreciation rates, market value per unit of assets of mature firms does not converge; neither does firm size. As a benchmark, I set identical depreciation rate for physical and intangible assets $\delta_{a}=\delta_{k}=\delta$. I choose $\delta=0.08$, which is within the range of depreciation rates estimated from the data on physical assets. I also experiment with higher values for $\delta_{a} \cdot{ }^{25}$

Using imputed physical and intangible assets, the share of physical assets in total assets is defined as $\tau_{i t} \equiv k_{i t} /\left(k_{i t}+a_{i t}\right)$, so the share of intangible assets is $1-\tau_{i t}$. Growth in physical assets is defined as $g_{k, i t}=\left(k_{i t+1}-k_{i t}\right) / k_{i t}$. Growth rates of other variables are defined similarly. Age is defined as the number of years (plus one) since the year of the company's initial public offering (IPO). The year of IPO is approximated with the earliest of (a) the year in which the firm appears on CRSP; (b) the year in which the firm is included in Compustat; and (c) the year for which a valid link is found between CRSP and Compustat (based on item LINKDT). I describe the measurement of other variables in the Appendix.

\section{B Empirical Findings and Tests of Model Implications}

\section{Characteristics of Physical and Intangible Assets}

The first important observation is that the share of intangible assets shows substantial crosssectional variations. Figure 6 plots the distribution and kernel density estimation for the asset

\footnotetext{
${ }^{25}$ To examine how the choice of $\delta_{a}$ and $\delta_{k}$ affects the empirical results, I first check that by setting $\delta_{a}=\delta_{k}=$ 0.08 , the data shows convergence in the market value per unit of assets and firms size among unconstrained firms with different asset composition. I also experiment with alternative empirical measures of intangible assets by setting different values for $\delta_{a}$ up to 0.35 . I find that most of the empirical results in the paper remains qualitatively the same. This is not surprising because $\delta_{a}$ mostly affect the size variation in asset composition. The qualitative relationship between asset composition and firm dynamics should not be affected.
} 
Figure 6: Asset Tangibility Distribution Among Entrants

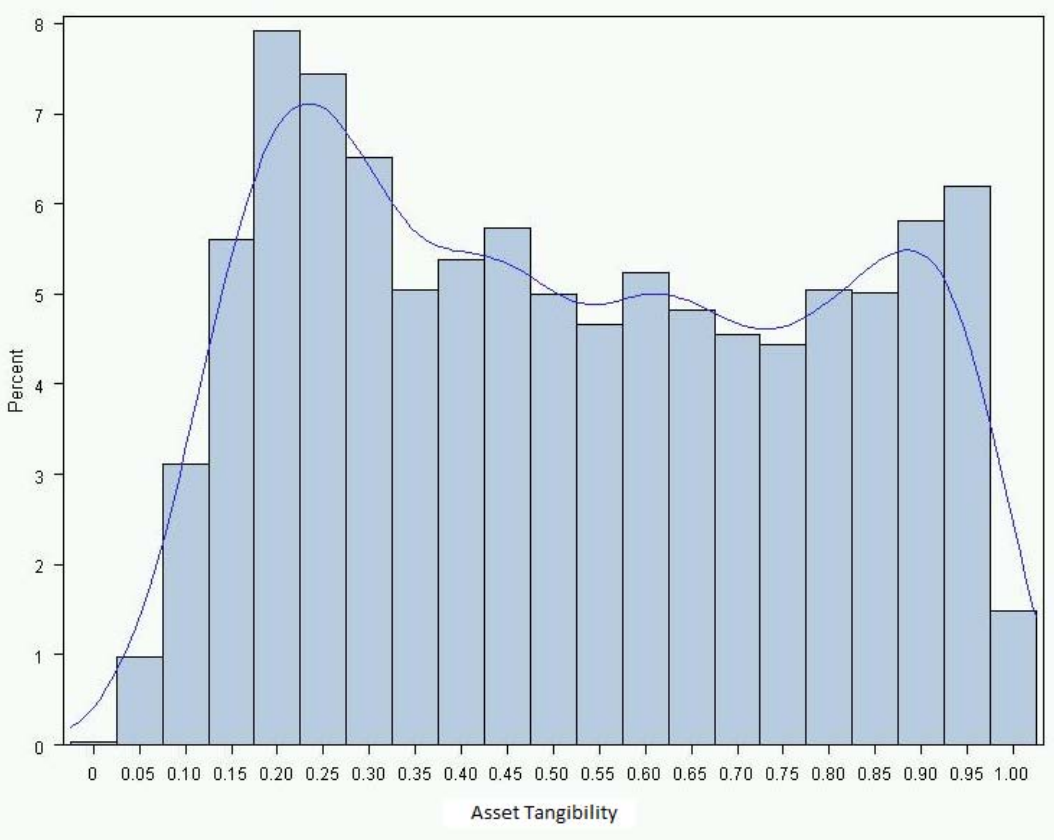

tangibility measure $\tau=k /(k+a)$ among entrant firms. $\tau$ ranges from below $5 \%$ to above $95 \%$. A substantial, and nearly constant, fraction of the sample spread across every bin of the histogram between $10 \%$ and $90 \%$. A relatively larger fraction of the sample has $\tau$ between $15 \%$ and $25 \%$. To examine the dynamics of $\tau$, I classify firms into three classes according to their initial share of intangible assets. The sample of firms is restricted to those with observation at age 1 . The class of firms with a high share of intangible assets includes firms whose initial $\tau$ is less than or equal to 0.4 ; the class with a low share of intangible, above 0.7 ; and the class with a medium share of intangible assets, between 0.4 and 0.7. As shown in the upper left panel of Figure 1, this initial difference in asset tangibility persists even among older firms. ${ }^{26}$

\section{Intangible Assets and Firm Dynamics}

This subsection presents the key empirical findings of the paper. The goal is to document a systematic relationship between intangible assets and firm dynamics. To help illustrate key findings before proceeding to a more formal analysis, Figure 1 plots the mean of several variables of interest for different classes of intangible shares. The upper right and middle left panels of Figure 1 plots firm size (the natural logarithm of sales and employment) for firms with a high, medium, and low share of intangible assets. Several observations emerge. First, young firms are smaller on average. This general pattern holds for firms in all classes. Second, a substantial size premium exists: Among entrants, firms with a low share of intangible

\footnotetext{
${ }^{26}$ I also regress asset composition on age using fixed effects estimations with year fixed effects and firm fixed effects. The coefficient on age is close to zero (0.0004), which again suggests that the age variation in asset composition is very small.
} 
assets are on average 6 times as large as firms with a high share of intangible assets. The size premium diminishes over time: Among older firms, firm size more or less converges. The first observation implies an inverse age and size relationship that is consistent with the literature. The second and third observations are the key: Substantial heterogeneity exists in the size of young firms, and this heterogeneity is related to the share of intangible assets in total assets. The size difference diminishes over time and exhibits convergence inertia.

The middle right panel of Figure 1 plot growth in total assets. Similar patterns emerge. First, young firms grow fast on average. Growth rate drops substantially as age increases. Second, an initial growth rate premium exists. Among entrants, firms with a high share of intangible assets grow faster on average. Third, the growth rate premium diminishes over time. The average growth rate of different classes converges among old firms.

The lower left panel of Figure 1 plots Tobin's q. Among young age categories, firms with a higher share of intangible assets on average have higher market value per unit of assets. Although this value falls among firms in all three classes, it remains permanently higher for firms with a low share of physical assets. This is in contrast with the lower right panel of Figure 1, which shows that the market value per unit of total assets converges among old firms. This result may not seem surprising given previous discussions on the two different $q$ measures. Nevertheless, this result cannot be derived from a standard q-theory model (e.g., Hayashi (1982) and Summers (1981)). The finding that the market value per unit of physical assets is significantly higher among firms with large shares of intangible assets suggests that the market value captures the value of intangible assets. It also suggests that including intangible assets in the model is essential in order to explain the heterogeneity in the market value of old firms.

The rest of this subsection describes the tests of the following hypotheses:

Hypothesis 1 (asset tangibility and firm dynamics): Among entrants, firms with a higher share of intangible assets on average have higher growth rate, smaller size, higher Tobin's q and higher market value per unit of assets (i.e. intangible adjusted q).

Hypothesis 2 (the diminishing effect of asset tangibility): The sensitivity of firm growth and size with respect to the share of intangible assets diminishes with age.

Hypotheses 1 and 2 follow directly from Proposition 7. Among young cohorts, the share of intangible assets predicts the probability of being financially constrained. Because the constrained status of a firm is reflected in it growth rate, firm size and market value per unit of assets, the share of intangible assets also predicts these aspects of firm dynamics. The predictive power diminishes as the firm ages and becomes constrained.

To test Hypothesis 1, I estimate the following regression model using the sample of entrant firms.

$$
y_{i j t}=\alpha_{0}+\alpha_{1} \tau_{i j t}+\mu_{j}+\theta_{t}+\varepsilon_{i j t}
$$

where $i, t$ and $j$ denote firm, year, and industry respectively. $y$ is the variable of interest: firm 
size, growth, Tobin's q, or intangible adjusted q. I use different measures for size ${ }_{i t}$ : the natural logarithm of (i) physical assets, (ii) total assets, (iii) sale, and (iv) employment. $\tau_{i j t}$ is the share of physical assets in total assets. Because entrant size varies by industry, I control for detailed industry fixed effects. ${ }^{27}$ I also control for year fixed effects to abstract from cyclical consideration. I use four different measures of firm size: the size of physical assets, total assets, employment, and sales. As shown in columns (1) to (4) Table 2. $\tau$ returns positive and significant coefficients for all measures of firm size. The model explains a significant fractions of the variance in all specifications. $\tau$ alone explains $13 \%$ and $8 \%$ of the variance in entrants' employment and sales.

I use two measures for the dependent variable: growth in physical assets and growth in total assets. As shown in columns (5) and (6) of Table 2, $\tau$ returns positive and significant coefficients in both specifications. Similar to the size regression in (25), the model explains a sizable fraction of the variance in entrant growth. $\tau$ alone explains $4 \%$ of the variance in the growth in physical assets and $17 \%$ of the variance in the growth in total assets.

Columns (8) and (9) of Table 2 summarizes results for the Tobin's q and intangible adjusted q regressions. The coefficients of $\tau$ in both cases are negative and significant. $\tau$ alone explains $26 \%$ of the variance in Tobin's $q$ and $7 \%$ of the variance in intangible adjusted $q$.

To test Hypothesis 2, I pool all firm-year observations and estimate the following regression model:

$$
y_{i t s}=\alpha_{0}+\alpha_{1 s} A g e_{s}+\alpha_{2 s} \tau_{i t s} \times A g e_{s}+\alpha_{3} \tau_{i t s}+\mu_{i}+\theta_{t}+\varepsilon_{i t s},
$$

where $y$ is the variable of interest: firm size, growth, Tobin's q, or intangible adjusted q. Age is a set of dummy variables, which take a value of 1 if age equals $s$ and 0 otherwise. $\tau_{i t s}$ is the share of physical assets in total assets. To investigate the short-run and long-run effects of $\tau$, I run the regression, using two measures: current $\tau$ or initial $\tau$. Current $\tau$ is the share of physical assets in total assets measured in the current year; initial $\tau$ is measured upon entry and restricted to the sample of firms with observation at age 1. I control for year and industry fixed effects.

Estimation results are summarized in Table 3 and 4. I only report coefficients of $\tau_{i t s}$ and selected age categories of $\tau_{i t s} \times A g e_{s}$ for space considerations. Note that the sum of coefficients $\left(\alpha_{2 s}+\alpha_{3}\right)$ represent the marginal effect of $\tau$ on the left-hand-side variable for age $s$. Because the model uses age 1 as the default category for the set of age dummy variables, the coefficient $\alpha_{2 s}$ also represents the average difference in the marginal effect of $\tau$ between age $s$ and age 1 firms. Starting from of column (1) of Table 3, the coefficient on current $\tau$ is positive and significant, suggesting that entrant firms with a higher share of physical assets on average have larger a larger stock of physical assets. The coefficients on $\tau \times A g e$ are negative and significant for all ages and are progressively smaller for older age categories. This result suggests that the marginal effect of tangibility on firm size diminishes as age increases. Column (3) and (5) show that similar patterns hold in terms of total assets and sales in general. Similar results hold

\footnotetext{
${ }^{27}$ Industry fixed effects are based on the 17-industry classification following Fama and French (1997).
} 
with initial $\tau$ as shown in columns (2), (4), and (6). The coefficients on $\tau \times$ Age are negative

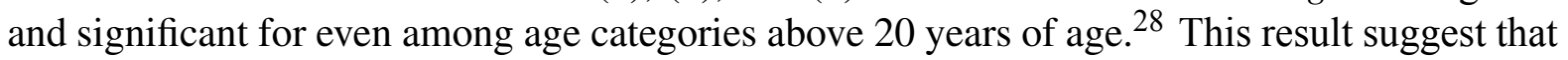
initial asset tangibility has long lasting effects on firms size.

I do not discuss detailed results of Table 4 for brevity of discussion. Overall, the diminishing age effects of tangibility discussed previously carry over to models with firm growth, Tobin's q and intangible adjusted $\mathrm{q}$. The regression results confirm the stylized facts on asset tangibility, firm dynamics and q illustrated in 1.

\section{Robustness}

Robustness to Other Measures of Assets Previous results are robust to alternative measures of assets. I measure physical assets by their reported book value (item PPEGT) and use the ratio of reported physical and total assets (i.e., $\hat{\tau} \equiv$ PPEGT/AT) as an indication of the asset tangibility. Because the reported total assets include current assets (e.g., inventory and cash) but not internally generated intangible assets, it is a noisy measure of the firm's total productive assets. Nevertheless, if the market (e.g., equity traders and lenders) uses this information and the share of intangible assets indeed affects investment and lending decisions, it is likely that $\hat{\tau}$ is correlated with firm dynamics. I perform the same regression analyses using $\hat{\tau}$ in place of $\tau$. Estimation results show that the coefficients of $\hat{\tau}$ are in the same direction as those for $\tau$ but the coefficients of $\hat{\tau}$ are generally smaller. Moreover, the $R^{2}$ from models using $\hat{\tau}$ are generally smaller.

Robustness to Other Explanations One important theoretical explanation of the size and growth dynamics is the selection theory: Some firms are more likely to exit perhaps because of adverse shocks and tend to have higher growth and higher market value conditional on survival. If the selection effect is higher among firms with a higher share of intangible assets, it may confound the effect of financial frictions. Fortunately, this is not the case. I estimate a binomial model and find that firms with a higher share of intangible assets on average are less likely to exit. 29

\section{CONCLUSION}

I study the effects of asset tangibility on firm dynamics in the presence of endogenous financial frictions. I present new evidence on the age and asset tangibility effects of firm size, growth, and Tobin's q, and show that it can be explained by a model of limited contract enforcement. I have chosen to keep the model as simple as possible, extending a standard model with the minimum elements needed to derive new implications. In spite of its simplicity, the model matches

\footnotetext{
${ }^{28}$ The only exception is that the initial $\tau \times$ Age is negative but not significant for young age categories. This may be because young firms experience large volatility in sales.

${ }^{29}$ Exit is defined when a firm drops out of the sample. In the Compustat data, this may mean a firm stops operation, a firm exits the stock market, or it is merged or acquired by another firm.
} 
a rich set of the properties of firm dynamics that have been documented here or previously in the literature. I have shown that modeling the accumulation of intangible assets is crucial for explaining the level and age dynamics of Tobin's q. By exploring properties of heterogeneous firms, the model also offers a new set of testable implications for financial constraints.

In this paper, I mainly focus on the age dynamics of firms and present the majority set of new evidence by age categories. Clearly, age is not the only dimension of firm growth. Older firms acquire younger firms all the time, allowing them to update their technology or to expand their market share. In this case, firm age, size and financial constraints do not necessarily follow a monotonic relationship. Simple extensions can accommodate this by distinguishing a firm from a production technology. A firm can be allowed to expand (e.g., by acquiring new production units) or to switch (e.g., by changing their main line of production) its production technology.

There are other interesting extensions. For instance, aggregate fluctuations can be accommodated, the framework I propose in this paper can prove useful in analyzing the cyclicality of firm dynamics and studying the growth impact of severe financial constraints during a recession. 
Table 1: Estimated Physical Depreciation Rate

\begin{tabular}{ccc}
\hline \hline Industry & Mean & No. of \\
\hline Food & 0.072 & 3,030 \\
Mines & 0.102 & 1,065 \\
Oil & 0.098 & 3,644 \\
Clothes & 0.084 & 2,562 \\
Durables & 0.081 & 3,180 \\
Chemicals & 0.075 & 1,785 \\
Consumption goods & 0.082 & 2,948 \\
Construction & 0.082 & 3,646 \\
Steel & 0.065 & 1,629 \\
Fabricated products & 0.069 & 1,053 \\
Machinery & 0.076 & 13,838 \\
Automobile & 0.063 & 1,290 \\
Transportation & 0.079 & 3,414 \\
Retail & 0.076 & 6,081 \\
Other & 0.097 & 28,076 \\
\hline
\end{tabular}

Notes: This table reports results from fixed effects estimation with robust standard errors. The dependent variables are the natural logarithm of physical assets (column 1 and 2), the stock of physical and intangible assets (column 3 and 4), and sales (column 5 and 6). Tangibility is defined as the ratio of physical assets to the stock of physical and intangible assets. Current tangibility is measured at the beginning of the year. Initial tangibility is measured at age 1 . All variables are winsorized at the 2 and 98 percent. All models are estimated with year and industry fixed effects. Coefficients are omitted for Age and Tangibility*Age for some age categories. ***,**, and * indicate statistical significance at the 1,5 , and 10 percent test levels, respectively. 
Table 2: Entrant Asset Tangibility, Firm Dynamics, and Q

\begin{tabular}{|c|c|c|c|c|c|c|c|c|}
\hline & $\begin{array}{c}\text { Physical } \\
\text { assets } \\
\text { (1) }\end{array}$ & $\begin{array}{l}\text { Total } \\
\text { assets } \\
\text { (2) }\end{array}$ & Employment & Sales & $\begin{array}{l}\text { Physical } \\
\text { assets } \\
\text { growth } \\
\text { (5) }\end{array}$ & $\begin{array}{c}\text { Total } \\
\text { assets } \\
\text { growth } \\
\text { (6) }\end{array}$ & Tobin's q & $\begin{array}{c}\text { Intangible } \\
\text { adjusted q } \\
\text { (9) }\end{array}$ \\
\hline Tangibility & $\begin{array}{c}5.6203 * * * \\
{[0.1376]}\end{array}$ & $\begin{array}{c}3.2812 * * * \\
{[0.1368]}\end{array}$ & $\begin{array}{c}2.9554 * * * \\
{[0.1449]}\end{array}$ & $\begin{array}{c}2.5936 * * * \\
{[0.1614]}\end{array}$ & $\begin{array}{c}-0.2579 * * * \\
{[0.0261]}\end{array}$ & $\begin{array}{c}-0.5308 * * * \\
{[0.0229]}\end{array}$ & $\begin{array}{c}-29.9738 * * * \\
{[0.8465]}\end{array}$ & $\begin{array}{c}-2.5915 * * * \\
{[0.1732]}\end{array}$ \\
\hline Constant & $\begin{array}{c}0.2796^{* * *} \\
{[0.0659]}\end{array}$ & $\begin{array}{c}2.3605 * * * \\
{[0.065]}\end{array}$ & $\begin{array}{c}-2.461 * * * \\
{[0.0721]}\end{array}$ & $\begin{array}{c}2.4542 * * * \\
{[0.0841]}\end{array}$ & $\begin{array}{c}0.4989 * * * \\
{[0.0144]}\end{array}$ & $\begin{array}{c}0.8580^{* * * *} \\
{[0.0115]}\end{array}$ & $\begin{array}{c}26.6232 * * * \\
{[0.5494]}\end{array}$ & $\begin{array}{c}4.3454 * * * \\
{[0.1003]}\end{array}$ \\
\hline No. of obs. & 2,593 & 2,593 & 2,593 & 2,593 & 2,530 & 2,530 & 2,593 & 2,593 \\
\hline$R^{2}$ & 0.6237 & 0.4771 & 0.4130 & 0.4102 & 0.2507 & 0.4488 & 0.5213 & 0.3297 \\
\hline$R^{2}$ for tangibility & 0.3368 & 0.1685 & 0.1294 & 0.078 & 0.0365 & 0.1707 & 0.2569 & 0.0666 \\
\hline
\end{tabular}

Notes: This table reports results from fixed effects estimation with robust standard errors. The dependent variable in columns 1 and 2 is the growth rate of the stock of physical and intangible assets. The dependent variable in columns 3 and 4 is the stock of physical and intangible assets. The dependent variable in columns 5 and 6 is then ratio of the market value of the firm to the stock of physical and intangible assets. Tangibility is defined as the ratio of physical assets to the stock of physical and intangible assets. All variables are winsorized at the 2 and 98 percent.

Specifications with current tangibility is estimated with year and industry fixed effects. Standard errors are clustered at the firm level. ***,**, and * indicate statistical significance at the 1,5 , and 10 percent test levels, respectively. 
Table 3: The Age Effects of Asset Tangibility on Firm Size

\begin{tabular}{|c|c|c|c|c|c|c|}
\hline \multirow{3}{*}{ Tangibility $(\tau)$} & \multicolumn{2}{|c|}{ Physical assets } & \multicolumn{2}{|c|}{ Total assets } & \multicolumn{2}{|c|}{ Sales } \\
\hline & $\begin{array}{c}\text { Current } \tau \\
\text { (1) }\end{array}$ & $\begin{array}{c}\text { Initial } \tau \\
\text { (2) }\end{array}$ & $\begin{array}{c}\text { Current } \tau \\
\text { (3) }\end{array}$ & $\begin{array}{c}\text { Initial } \tau \\
(4)\end{array}$ & $\begin{array}{c}\text { Current } \tau \\
\text { (5) }\end{array}$ & $\begin{array}{c}\text { Initial } \tau \\
(6)\end{array}$ \\
\hline & $\begin{array}{c}5.3048^{* * *} \\
{[0.1112]}\end{array}$ & $\begin{array}{c}5.4477 * * * \\
{[0.1100]}\end{array}$ & $\begin{array}{c}2.9619^{* * *} \\
{[0.1106]}\end{array}$ & $\begin{array}{c}3.1862 * * * \\
{[0.1086]}\end{array}$ & $\begin{array}{c}2.2653 * * * \\
{[0.1340]}\end{array}$ & $\begin{array}{c}2.551 \\
{[0.1312]}\end{array}$ \\
\hline$\tau *$ Age 2 & $\begin{array}{c}-0.3383 * * * \\
{[0.1462]}\end{array}$ & $\begin{array}{l}-0.2069 \\
0.1535]\end{array}$ & $\begin{array}{c}-0.4804 * * * \\
{[0.1447]}\end{array}$ & $\begin{array}{c}-0.3712^{* *} \\
{[0.1504]}\end{array}$ & $\begin{array}{c}-0.3534 * * * \\
{[0.1742]}\end{array}$ & $\begin{array}{c}-0.1494 \\
{[0.1819]}\end{array}$ \\
\hline$\tau *$ Age 3 & $\begin{array}{c}-0.2909 * * * \\
{[0.1480]}\end{array}$ & $\begin{array}{c}-0.2451 \\
{[0.1613]}\end{array}$ & $\begin{array}{c}-0.5923 * * * \\
{[0.1467]}\end{array}$ & $\begin{array}{c}-0.5345^{* * *} \\
{[0.1569]}\end{array}$ & $\begin{array}{c}-0.3476^{* * *} \\
{[0.1769]}\end{array}$ & $\begin{array}{c}-0.1070 \\
{[0.1891]}\end{array}$ \\
\hline$\tau *$ Age 4 & $\begin{array}{c}-0.4051 * * * \\
{[0.1549]}\end{array}$ & $\begin{array}{c}-0.4003 * * \\
{[0.1727]}\end{array}$ & $\begin{array}{c}-0.7964 * * * \\
{[0.1537]}\end{array}$ & $\begin{array}{c}-0.6880 * * * \\
{[0.1673]}\end{array}$ & $\begin{array}{c}-0.5170^{* * *} \\
{[0.1821]}\end{array}$ & $\begin{array}{c}-0.1800 \\
{[0.1979]}\end{array}$ \\
\hline$\tau *$ Age 5 & $\begin{array}{c}-0.4291 * * * \\
{[0.1617]}\end{array}$ & $\begin{array}{c}-0.5064 * * * \\
{[0.1844]}\end{array}$ & $\begin{array}{c}-0.8914 * * * \\
{[0.1602]}\end{array}$ & $\begin{array}{c}-0.7768 * * * \\
{[0.1770]}\end{array}$ & $\begin{array}{c}-0.5632 * * * \\
{[0.1891]}\end{array}$ & $\begin{array}{c}-0.2123 \\
{[0.2070]}\end{array}$ \\
\hline$\tau *$ Age 6 & $\begin{array}{c}-0.3854 * * * \\
{[0.1669]}\end{array}$ & $\begin{array}{c}-0.4000^{* *} \\
{[0.1957]}\end{array}$ & $\begin{array}{c}-0.8520^{* * *} \\
{[0.1651]}\end{array}$ & $\begin{array}{c}-0.6293 * * * \\
{[0.2067]}\end{array}$ & $\begin{array}{c}-0.5467 * * * \\
{[0.1948]}\end{array}$ & $\begin{array}{c}-0.0296 \\
{[0.2183]}\end{array}$ \\
\hline$\tau *$ Age 11 & $\begin{array}{c}-0.4618 * * * \\
{[0.1764]}\end{array}$ & $\begin{array}{c}-0.6633 * * * \\
{[0.2593]}\end{array}$ & $\begin{array}{c}-0.8124 * * * \\
{[0.1724]}\end{array}$ & $\begin{array}{c}-0.7508 * * * \\
{[02446]}\end{array}$ & $\begin{array}{c}-0.6620 * * * \\
{[0.2000]}\end{array}$ & $\begin{array}{c}-0.3799 \\
{[0.2513]}\end{array}$ \\
\hline$\tau *$ Age 16 & $\begin{array}{c}-0.4044 * * * \\
{[0.2192]}\end{array}$ & $\begin{array}{c}-1.2583 * * * \\
{[0.4309]}\end{array}$ & $\begin{array}{c}-0.7380^{* * *} \\
{[0.2143]}\end{array}$ & $\begin{array}{c}-1.0545 * * * \\
{[0.3873]}\end{array}$ & $\begin{array}{c}-0.7245^{* * *} \\
{[0.2384]}\end{array}$ & $\begin{array}{l}-0.4033 \\
{[0.4275]}\end{array}$ \\
\hline$\tau *$ Age 21 & $\begin{array}{c}-0.7892 * * * \\
{[0.2544]}\end{array}$ & $\begin{array}{c}-2.7893 * * * \\
{[0.7881]}\end{array}$ & $\begin{array}{c}-1.1678 * * * \\
{[0.2447]}\end{array}$ & $\begin{array}{c}-2.2548 * * * \\
{[0.6747]}\end{array}$ & $\begin{array}{c}-1.2111^{* * *} \\
{[0.2706]}\end{array}$ & $\begin{array}{c}-1.4935^{* *} \\
{[0.7268]}\end{array}$ \\
\hline$\tau *$ Age 26 & $\begin{array}{c}-0.6882 * * * \\
{[0.2981]}\end{array}$ & $\begin{array}{c}-3.7470 * * * \\
{[1.3480]}\end{array}$ & $\begin{array}{c}-1.0617 * * * \\
{[0.2844]}\end{array}$ & $\begin{array}{c}-3.0863 * * * \\
{[1.0136]}\end{array}$ & $\begin{array}{c}-1.1987 * * * \\
{[0.3210]}\end{array}$ & $\begin{array}{c}-2.2305^{* *} \\
{[1.0864]}\end{array}$ \\
\hline$\tau *$ Age 31 & $\begin{array}{c}-1.1126^{* * *} * \\
{[0.3545]}\end{array}$ & $\begin{array}{c}-4.6057 * * * \\
{[1.1427]}\end{array}$ & $\begin{array}{c}-1.3502 * * * \\
{[0.3432]}\end{array}$ & $\begin{array}{c}-5.3452 * * * \\
{[0.7630]}\end{array}$ & $\begin{array}{c}-0.1512 * * * \\
{[0.3658]}\end{array}$ & $\begin{array}{c}-5.1937 * * * \\
{[0.5563]}\end{array}$ \\
\hline No. of Obs. & 63,907 & 20,434 & 63,907 & 20,434 & 63,907 & 20,434 \\
\hline $\begin{array}{c}\text { No. of F.E. } \\
R^{2}\end{array}$ & $\begin{array}{c}465 \\
0.5216\end{array}$ & $\begin{array}{c}453 \\
0.4716\end{array}$ & $\begin{array}{c}465 \\
0.3785\end{array}$ & $\begin{array}{c}453 \\
0.3399\end{array}$ & $\begin{array}{c}465 \\
0.3785\end{array}$ & $\begin{array}{c}453 \\
0.3146\end{array}$ \\
\hline
\end{tabular}

Notes: This table reports results from fixed effects estimation with robust standard errors. The dependent variables are the natural logarithm of physical assets (column 1 and 2), the stock of physical and intangible assets (column 3 and 4), and sales (column 5 and 6). Tangibility is defined as the ratio of physical assets to the stock of physical and intangible assets. Current tangibility is measured at the beginning of the year. Initial tangibility is measured at age 1. All variables are winsorized at the 2 and 98 percent. All models are estimated with year and industry fixed effects. Coefficients are omitted for Age and Tangibility*Age for some age categories. $* * *, * *$, and * indicate statistical significance at the 1,5 , and 10 percent test levels, respectively. 
Table 4: The Age Effects of Asset Tangibility on Firm Growth and Q

\begin{tabular}{|c|c|c|c|c|c|c|}
\hline & \multicolumn{2}{|c|}{ Growth in total assets } & \multicolumn{2}{|c|}{ Tobin's q } & \multicolumn{2}{|c|}{ Intangible adjusted q } \\
\hline & $\begin{array}{l}\text { Current } \tau \\
\text { (1) }\end{array}$ & $\begin{array}{l}\text { Initial } \tau \\
\text { (2) }\end{array}$ & $\begin{array}{l}\text { Current } \tau \\
\text { (3) }\end{array}$ & $\begin{array}{l}\text { Initial } \tau \\
\text { (4) }\end{array}$ & $\begin{array}{c}\text { Current } \tau \\
\text { (5) }\end{array}$ & $\begin{array}{c}\text { Initial } \tau \\
\text { (5) }\end{array}$ \\
\hline Tangibility $(\tau)$ & $\begin{array}{c}-0.5634^{* * * *} \\
{[0.0184]}\end{array}$ & $\begin{array}{c}-0.5535^{* * * *} \\
{[0.0184]}\end{array}$ & $\begin{array}{c}-30.2926^{* * * * *} \\
{[0.6939]}\end{array}$ & $\begin{array}{c}-29.7973 * * * \\
{[0.6998]}\end{array}$ & $\begin{array}{c}-2.9435^{* * *} \\
{[0.1355]}\end{array}$ & $\begin{array}{c}-2.8724^{* * * *} \\
{[0.1365]}\end{array}$ \\
\hline$\tau *$ Age 2 & $\begin{array}{c}0.2259 * * * \\
{[0.0253]}\end{array}$ & $\begin{array}{c}0.2583 * * * \\
{[0.0239]}\end{array}$ & $\begin{array}{c}10.9938^{* * * *} \\
{[0.8853]}\end{array}$ & $\begin{array}{c}12.9695 * * * \\
{[0.9467]}\end{array}$ & $\begin{array}{c}1.8240^{* * * *} \\
{[0.1687]}\end{array}$ & $\begin{array}{c}2.0536 * * * \\
{[0.1741]}\end{array}$ \\
\hline$\tau *$ Age 3 & $\begin{array}{c}0.3832 * * * \\
{[0.0228]}\end{array}$ & $\begin{array}{c}0.4165 * * * \\
{[0.0235]}\end{array}$ & $\begin{array}{c}14.8272 * * * \\
{[0.8694]}\end{array}$ & $\begin{array}{c}16.0657 * * * \\
{[0.9616]}\end{array}$ & $\begin{array}{c}2.4254^{* * * *} \\
{[0.1609]}\end{array}$ & $\begin{array}{c}2.6764 * * * \\
{[0.1708]}\end{array}$ \\
\hline$\tau *$ Age 4 & $\begin{array}{c}0.4678^{* * * *} \\
{[0.0225]}\end{array}$ & $\begin{array}{c}0.4870 * * * \\
{[0.0236]}\end{array}$ & $\begin{array}{c}17.4802 * * * * \\
{[0.8617]}\end{array}$ & $\begin{array}{c}18.2333 * * * \\
{[0.9906]}\end{array}$ & $\begin{array}{c}2.7741^{* * * *} \\
{[0.1606]}\end{array}$ & $\begin{array}{c}2.8512^{* * *} \\
{[0.1770]}\end{array}$ \\
\hline$\tau *$ Age 5 & $\begin{array}{c}0.5199^{* * * *} \\
{[0.0226]}\end{array}$ & $\begin{array}{c}0.5097 * * * \\
{[0.0242]}\end{array}$ & $\begin{array}{c}18.3094 * * * \\
{[0.8701]}\end{array}$ & $\begin{array}{c}19.6225^{* * *} \\
{[1.0089]}\end{array}$ & $\begin{array}{c}2.9448^{* * * *} \\
{[0.1609]}\end{array}$ & $\begin{array}{c}2.9813 * * * \\
{[0.1805]}\end{array}$ \\
\hline$\tau *$ Age 6 & $\begin{array}{c}0.5269^{* * * *} \\
{[0.0221]}\end{array}$ & $\begin{array}{c}0.5325 * * * \\
{[0.0237]}\end{array}$ & $\begin{array}{c}18.7522 * * * \\
{[0.8854]}\end{array}$ & $\begin{array}{c}20.0272^{* * * *} \\
{[1.0369]}\end{array}$ & $\begin{array}{c}2.9175^{* * *} \\
{[0.1610]}\end{array}$ & $\begin{array}{c}2.9343 * * * \\
{[0.1837]}\end{array}$ \\
\hline$\tau *$ Age 11 & $\begin{array}{c}0.5082 * * * \\
{[0.0222]}\end{array}$ & $\begin{array}{c}0.5435 * * * \\
{[0.0255]}\end{array}$ & $\begin{array}{c}21.1953 * * * \\
{[0.9052]}\end{array}$ & $\begin{array}{c}22.0190^{* * *} \\
{[1.2058]}\end{array}$ & $\begin{array}{c}3.0076^{* * *} \\
{[0.1580]}\end{array}$ & $\begin{array}{c}3.0134 * * * \\
{[0.2060]}\end{array}$ \\
\hline$\tau *$ Age 16 & $\begin{array}{c}0.5452^{* * * *} \\
{[0.0223]}\end{array}$ & $\begin{array}{c}0.5786^{* * *} \\
{[0.0317]}\end{array}$ & $\begin{array}{c}21.0106^{* * *} \\
{[1.0761]}\end{array}$ & $\begin{array}{c}23.7171 * * * \\
{[2.0176]}\end{array}$ & $\begin{array}{c}2.9100^{* * *} \\
{[0.1655]}\end{array}$ & $\begin{array}{c}3.2437 * * * \\
{[0.2669]}\end{array}$ \\
\hline$\tau *$ Age 21 & $\begin{array}{c}0.5435^{* * *} \\
{[0.0236]}\end{array}$ & $\begin{array}{c}0.6156^{* * *} \\
{[0.0467]}\end{array}$ & $\begin{array}{c}21.2679^{* * *} \\
{[1.1776]}\end{array}$ & $\begin{array}{c}25.7993 * * * \\
{[2.9833]}\end{array}$ & $\begin{array}{c}2.8681^{* * *} \\
{[0.1741]}\end{array}$ & $\begin{array}{c}3.3122^{* * *} \\
{[0.3153]}\end{array}$ \\
\hline$\tau *$ Age 26 & $\begin{array}{c}0.5380^{* * *} \\
{[0.0244]}\end{array}$ & $\begin{array}{c}0.5923 * * * \\
{[0.0742]}\end{array}$ & $\begin{array}{c}20.3719^{* *} \\
{[1.3793]}\end{array}$ & $\begin{array}{c}32.3260^{* * * *} \\
{[6.2074]}\end{array}$ & $\begin{array}{c}2.7382^{* * * *} \\
{[0.1980]}\end{array}$ & $\begin{array}{c}3.9059^{* * *} \\
{[0.8758]}\end{array}$ \\
\hline$\tau *$ Age 31 & $\begin{array}{c}0.5332^{* * *} \\
{[0.0261]}\end{array}$ & $\begin{array}{c}3.4415^{* * *} \\
{[0.8529]}\end{array}$ & $\begin{array}{c}20.9721^{* * *} \\
{[1.5149]}\end{array}$ & $\begin{array}{c}17.3713^{* * *} \\
{[9.0814]}\end{array}$ & $\begin{array}{c}2.5856^{* * *} \\
{[0.2022]}\end{array}$ & $\begin{array}{c}4.3005^{* * *} \\
{[0.1404]}\end{array}$ \\
\hline No. of Obs. & 57,412 & 17,782 & 63,907 & 20,434 & 63,907 & 20,434 \\
\hline No. of $\mathrm{F}$ & 450 & 437 & 465 & 453 & 465 & 453 \\
\hline$R^{2}$ & 0.5215 & 0.6194 & 0.3193 & 0.3244 & 0.2486 & 0.2804 \\
\hline
\end{tabular}

Notes: This table reports results from fixed effects estimation with robust standard errors. The dependent variables are the growth rate of total assets (column 1 and 2), Tobin's q (column 3 and 4), and intangible adjusted q (column 5 and 6). Tangibility is defined as the ratio of physical assets to the stock of physical and intangible assets. Current tangibility is measured at the beginning of the year. Initial tangibility is measured at age 1. All variables are winsorized at the 2 and 98 percent. All models are estimated with year and industry fixed effects. Coefficients are omitted for Age and Tangibility*Age for some age categories. ***,**, and * indicate statistical significance at the 1,5 , and 10 percent test levels, respectively. 


\section{Appendix I. Proofs}

Proof of Lemma 1. (i) $\pi(V, z)$ is weakly increasing in $V$ following the monotonicity of the constraint set. The weak monotonicity of $W(V, z)$ in $V$ follows immediately from the monotonicity of $\pi(V, z)$ in $V$ applying standard dynamic programming arguments. (ii) Suppose for all $V \geq \tilde{V}(z), W\left(V, z^{\prime}\right)=\tilde{W}\left(z^{\prime}\right)$ and $V\left(z^{\prime}\right)=\tilde{V}\left(z^{\prime}\right)$. (11) implies that

$$
\begin{aligned}
W(V, z) & =\mathbb{E}_{z^{\prime} \mid z}\left[\pi^{*}(z)+\beta W\left(\tilde{V}\left(z^{\prime}\right), z^{\prime}\right)\right] \\
& =\mathbb{E}_{z^{\prime} \mid z}\left[\pi^{*}(z)+\beta \tilde{W}\left(z^{\prime}\right)\right] \\
& =\tilde{W}(z) .
\end{aligned}
$$

(iii) If $V<\tilde{V}(z)$, then $V<V^{n}(z)$ for some $n$. I shall proceed with induction. For $n=1$, $V<V^{*}(z)$ implies $-R_{k} k^{\prime}-R_{a} a^{\prime}+\beta E_{z^{\prime} \mid z} F\left(k^{\prime}, a^{\prime}, z^{\prime}\right)<\pi^{*}(z)$. Abusing notation, let $V\left(z^{\prime}\right)$ be the optimal continuation value given $(V, z)$, then

$$
\begin{aligned}
W(V, z) & <\mathbb{E}_{z^{\prime} \mid z}\left[\pi^{*}(z)+\beta W\left(V\left(z^{\prime}\right), z^{\prime}\right)\right] \\
& \leq \mathbb{E}_{z^{\prime} \mid z}\left[\pi^{*}(z)+\beta \tilde{W}\left(z^{\prime}\right)\right] \\
& =\tilde{W}(z) .
\end{aligned}
$$

To proceed, suppose $V<V^{n-1}(z)$ implies $W(V, z)<\tilde{W}(z)$ for all $z \in Z$. For $V<V^{n}(z)$ to hold, one need $V<V^{*}(z)$ or $V<\beta E_{z^{\prime} \mid z} V^{n-1}\left(z^{\prime}\right)$. The proof for the former case follows the same argument as in $n=1$. For the latter, the continuation policy $V\left(z^{\prime}\right)$ is such that $V\left(z^{\prime}\right)<V^{n-1}\left(z^{\prime}\right)$ for some $z \in Z$ by induction, it follows that $V=\beta E_{z^{\prime} \mid z} V\left(z^{\prime}\right)<\beta E_{z^{\prime} \mid z} V^{n-1}\left(z^{\prime}\right) .{ }^{30}$

Proof of Lemma 2. This proof is similar to the proof of Lemma 3 in Appendix C in Albuquerque and Hopenhayn (2004). First, the indirect profit function $\pi(V, z)$ is strictly concave in $V$ following strict concavity of the production function $F($.$) and convexity of the constraint$ set. It follows that $W(V, z)$ is concave by Theorem 9.8 in Stokey, Lucas and Prescott (1989). If $V<\tilde{V}(z)$, then an $n$ exists such that $V<V^{n}(z)$. I shall proceed with induction on $n$ to show that this implies strictly concavity of $W(V, z)$ in the neighborhood of $V$. For $n=1, V<V^{n}(z)$ and strictly concavity of $W(V, z)$ in $V$ follows strict concavity of $\pi(V, z)$. Now suppose the result hold for all $z$ and $V<V^{n-1}(z)$ and $V^{u}(z) \leq V<V^{n}(z)$. The optimal continuation value $V^{\prime}\left(z^{\prime}\right)<V^{n-1}\left(z^{\prime}\right)$ on a subset of $s$ with positive measure given $s$. Strict concavity follows by inductions.

Proof of Lemma 3. Suppose some $V_{2}<V_{1}<\tilde{V}(z)$ exists such that $W\left(V_{2}, z\right)=W\left(V_{1}, z\right)$, then concavity of $W(V, z)$ implies $W\left(V_{2}, z\right)=W(\tilde{V}(z), z)$, which contradicts Lemma 1.

Proof of Lemma 4. Substituting (18) to (19) gives the left-hand side. Expanding and comparing terms with (11) establishes the equality.

The following proofs are based on a Cobb-Douglas production technology $F(k, a, \gamma)=e^{z}\left(k^{\gamma} a^{1-\gamma}\right)^{\theta}$ with deterministic $z$ and assumes $\eta_{k}=0$.

\footnotetext{
${ }^{30}$ The proof of (ii) and (iii) follows from Albuquerque and Hopenhayn (2004).
} 
Proof of Proposition 5. Suppose some $\gamma_{2}<\gamma_{1}$ and $V$ exist such that $V<\tilde{V}\left(\gamma_{1}\right)<\tilde{V}\left(\gamma_{2}\right)$. The indirect profit function is given by

$$
\pi(V, \gamma)=\max _{k^{\prime}, a^{\prime}}\left\{-R_{k} k^{\prime}-R_{k} a^{\prime}+\beta F\left(k^{\prime}, a^{\prime}, \gamma\right)\right\},
$$

subject to $V \geq \eta_{a} a^{\prime}$. Equality of the enforcement constraint implies that $a^{\prime}\left(V, \gamma_{1}\right)=a^{\prime}\left(V, \gamma_{2}\right)=$ $\frac{V}{\eta_{a}}$. It is easy to check that the optimality conditions for $k^{\prime}$ (i.e., $R_{k}=\beta \frac{\partial F\left(k^{\prime}, a^{\prime}, \gamma\right)}{\partial k^{\prime}}$ ) implies that $k^{\prime}(V, \gamma)$ is increasing in $\gamma$ and the indirect profit function can be simplified as $\pi(V, \gamma)=$ $\beta(1-\theta \gamma) F\left(k^{\prime}(V, \gamma), a^{\prime}(V, \gamma), \gamma\right)-R_{a} a^{\prime}(V, \gamma)$; so $\pi(V, \gamma)$ is increasing in $\gamma$ given $V$. Applying standard dynamic programming arguments, $W(., \gamma)$ is increasing in $\gamma$ following the monotonicity of $\pi(., \gamma)$ in $\gamma$. Since $B(V, \gamma)=W(V, \gamma)-V, B(., \gamma)$ is also increasing in $V$. By Lemma 2 and 3, $W(V, \gamma)$ is strictly increasing and strictly concave in $V$ in a region where $V<\tilde{V}(\gamma)$. It follows that $B(V, \gamma)$ is strictly concave in $V$ as well. Now consider the problem of entrants. Suppose $I_{0}$ is such that the debtholders' initial participation constrained is satisfies (i.e., $\left.B_{0}\left(V_{0}, \gamma\right) \geq I_{0}\right)$ for some $V_{0} \geq 0$ so the initial contract is signed. The optimal initial equity value $V_{0}(\gamma)$ is in a region where $B(V, \gamma)$ is decreasing in $V$. To see this, suppose otherwise. By the strictly concavity of $B(V, \gamma)$ in $V$, a $\hat{V}_{0}$ exists such that $\hat{V}_{0}>V_{0}$ and $B(\hat{V}, \gamma) \geq I_{0}$, which contradicts $V_{0}=\sup \left\{V: B\left(V_{0}, \gamma\right) \geq I_{0}\right\}$. It follows that $V$ maps one-to-one $B(V, \gamma)$, for all possible values of $V$ that satisfy the optimal contract. Now define the transformation $V=B^{-1}(B(V, \gamma), \gamma)$, where $B^{-1}(., \gamma)$ is the inverse function of $B(., \gamma)$. Total differentiation of the transformation function gives

$$
0=\frac{\partial B^{-1}(B, \gamma)}{\partial B} \frac{\partial B(V, \gamma)}{\partial \gamma}+\frac{\partial B^{-1}(B, \gamma)}{\partial \gamma}
$$

$\frac{\partial B^{-1}(B(V, \gamma), \gamma)}{\partial B}<0$ follows from the argument that $B(V, \gamma)$ is decreasing in $V$ and $\frac{\partial B(V, \gamma)}{\partial \gamma}>0$ as shown previously. It follows that $\frac{\partial V(B, \gamma)}{\partial \gamma}=\frac{\partial B^{-1}(B, \gamma)}{\partial \gamma}>0$, in particular $\frac{\partial V_{0}\left(I_{0}, \gamma\right)}{\partial \gamma}>0$, which says that given identical initial debt value (i.e. $I_{0}$ ), the initial equity value is increasing in $\gamma$; Following $V_{0}=\eta_{a} a_{1}$ and the monotonicity of $k^{\prime} / a^{\prime}$ in $\gamma$, entrant asset size is increasing in $\gamma$.

Proof of Proposition 4. Let $\lambda \geq 0$ denote the Lagrange multiplier for the enforcement constraint. The optimality conditions with respect to $k$ and $a$ imply $\frac{k}{a}=\frac{\gamma}{1-\gamma} \frac{R_{a}+\lambda \eta_{a}}{R_{k}+\lambda \eta_{k}}$. Conditional on $\gamma$, the size of physical assets relative to intangible assets is increasing in $\lambda$ if $\eta_{a}>\eta_{k}$ and $R_{a}=R_{k} \cdot{ }^{31}$ Recall from Lemma 2 and Lemma 3 that the total surplus value $W$ is strictly concave and strictly increasing in $V$. It follows that as the firm ages, the shadow value $\lambda$ decreases until the firm reaches the efficient frontier and $\lambda$ reaches 0 . As a result, a firm's share of physical assets is higher than its unconstrained level and fall monotonically until the firm becomes unconstrained.

\section{Appendix II. Variable Measurement}

Total debt is long-term debt (item DLTT) plus short-term debt (item DLC). Market value is defined as the sum of total debt, the market value of common equity (CRSP December market

\footnotetext{
${ }^{31} R_{a}=R_{k}$ holds when $\delta_{a}=\delta_{k}$.
} 
capitalization), and the book value of preferred stock (item PSTKRV), minus cash and shortterm investments (item CHE) and inventory (item INVT). Tobin's q is market value divided by physical assets. Cash flow is the sum of income before extraordinary items (item IB) and depreciation (item DP). Cash flow rate is cash flow divided by physical assets. To alleviate impacts of outliers, I windsorize growth and financial measures (including Tobin's q and market value to total assets) at $2 \%$ and $98 \%$.

Compustat reports both stock and flow variables at the end of year $t$. However, the model requires stock variables subscripted $t$ to be measured at the beginning of year $t$ and flow variables subscripted $t$ to be measured over the course of year $t$. I take any year $t$ stock variable, for example $k_{t}$, from the year $t-1$ balance sheet and any year $t$ flow variable from the year $t$ income or cash flow statement.

\section{Appendix III. Numerical Solution}

\section{A Calibration}

The period in the economy is one year. The interest rate is set to $r=0.04$. The probability of exit is set to $\varphi=0.1$, which implies a discount rate $\beta=0.865$. The production function is specified as $F(k, a, z)=Z e^{z}\left(k^{\gamma} a^{1-\gamma}\right)^{\theta}{ }^{32}$ This production function abstracts from labor input; nevertheless, $F($.$) can map to a production function with labor with an appropriate choice of$ $\theta$. For example, I can write the production function as $G(k, a, l, z)=e^{z}\left(k^{\gamma} a^{1-\gamma}\right)^{\theta} l^{\varepsilon-\theta}$ and set $\varepsilon=0.95$ so $G($.$) has a small degree of decreasing return. This parameterization makes$ the production function not too different from a standard constant return to scale function and is consistent with the literature (e.g. Gomes (2001)). Once $\varepsilon$ is determined, $\theta$ is set so the labor share is equal to 0.7 . This implies $\theta=0.25 .^{33}$ The firm-specific production parameter $\gamma$ is set matches the distribution of physical and intangible assets in the data. ${ }^{34} \mathrm{I}$ set $\delta_{k}=0.08$ and $\delta_{a}=0.08$. I assume that the stochastic process for incumbent productivity follows $z^{\prime}=\rho z+\varepsilon^{\prime}$, where $\varepsilon$ is assumed to follow a (truncated) normal distribution with mean zero, standard deviation $\sigma$ and finite support $[-2 \sigma, 2 \sigma]$. I discretize the stochastic process by two points following Tauchen (1991) and pick $\rho=0.40$ and $\sigma=0.05$ to match the mean and variance of investment rate among old firms. ${ }^{35}$ Finally, I discretize the state space of $V, V^{\prime}, k^{\prime}$ and $a^{\prime}$ into 90-point uniform grids.

\footnotetext{
${ }^{32}$ The parameter $Z$ is introduced to scale the average level of assets.

${ }^{33}$ Recall from the model's analytical results that the size convergence of firms with different $\gamma$ requires $\theta$ to be small. To check that $\theta=0.25$ is consistent with this implication, I simulate a sample of firm using this $\theta$ value and fixed all other parameters at their benchmark calibration value. I find that the variation of unconstrained total assets size with respect to $\gamma$ is small: The standard deviation is 0.11 and the average size of the medium class is $7 \%$ lower than that of the low class.

${ }^{34}$ I assume that $\gamma$ is drawn from a cumulative distribution function $H(\gamma)$, with support $[0.1,0.9]$. $H(\gamma)$ is set so that the model's distribution of physical and intangible assets among unconstrained firms matches the distribution of physical and intangible assets among old firms in the data. I discretize the support of $\gamma$ into 5 points.

${ }^{35}$ Specifically, I set $z_{1}=-2 \sigma, z_{2}=2 \sigma$ and the transitional probability from $z_{1}$ to $z_{1}$ is $p_{11}=\Phi(2 \rho)-$ $\Phi(-4+2 \rho)$. Entrant firm's productivity is drawn from a discrete uniform distribution over $\left[z_{1}, z_{2}\right]$.
} 
Table 5: Parameter values

\begin{tabular}{lll}
\hline \hline \multicolumn{3}{c}{ Calibrated parameters } \\
\hline Interest rate & $r$ & 0.04 \\
Exit rate & $\varphi$ & 0.10 \\
Return to scale & $\theta$ & 0.25 \\
Depreciation rate (physical) & $\delta_{k}$ & 0.08 \\
Depreciation rate (intangible) & $\delta_{a}$ & 0.08 \\
Shock persistence & $\rho$ & 0.40 \\
Stochastic shock variance & $\sigma$ & 0.05 \\
\multicolumn{1}{c}{ Estimated parameters } \\
& & \\
\hline Repudiation value (physical) & $\eta_{k}$ & 0.52 \\
Repudiation value (intangible) & $\eta_{a}$ & 0.87 \\
\hline
\end{tabular}

\section{B Solution Strategy}

I solve the model numerically using value function iteration on a multigrid scheme. Given the realization of firm-specific production technology and optimal decision rules, the model generates a simulated panel of firms. In particular, I simulate a model economy with 10,000 firms over 200 periods. I set $I_{0}=0$ and jointly calibrate parameters $\left\{\eta_{k}, \eta_{a}\right\}$ to match key moments of the simulated data, in particular, the size and growth rate premium associated with intangible asset.

\section{Identification}

The model's implications on the dynamics of heterogeneous firms are essential for the identification of structural parameters. It is worth noting that the set up cost $I_{0}$ and repudiation values $\eta_{k}$ and $\eta_{a}$ have similar implication and may not be identified separately in a model with representative firms; ${ }^{36}$ however, observations from heterogeneous firms can separately identify $I_{0}, \eta_{k}$, and $\eta_{a}$.

To see how identification results from the size premium associated with heterogeneous firms, suppose entrant firm sizes are observed for three classes of firms with different $\gamma$ denoted by $\{L, M, H\}$. Identical setup cost and the enforcement constraint imply

$$
B^{L}\left(\eta_{k} k^{L}+\eta_{a} a^{L} ; \eta_{k}, \eta_{a}\right)=B^{M}\left(\eta_{k} k^{M}+\eta_{a} a^{M} ; \eta_{k}, \eta_{a}\right)=B^{H}\left(\eta_{k} k^{H}+\eta_{a} a^{H} ; \eta_{k}, \eta_{a}\right)
$$

This equation identifies $\eta_{k}$ and $\eta_{a}$ using observed size differentials associated with $\gamma$. Once $\eta_{k}$ and $\eta_{a}$ are identified, the setup cost $I_{0}$ is the level of entrant debt $B^{L}()=.B^{M}()=.B^{H}()=.I_{0}$.

\footnotetext{
${ }^{36} I_{0}$ affects the initial size of entrant firms, which in turn affects the age of firms when they become unconstrained. $\eta_{k}$ and $\eta_{a}$ affect the entrant size and time to mature in similar manners as $I_{0}$.
} 
Figure 7: Model Identification
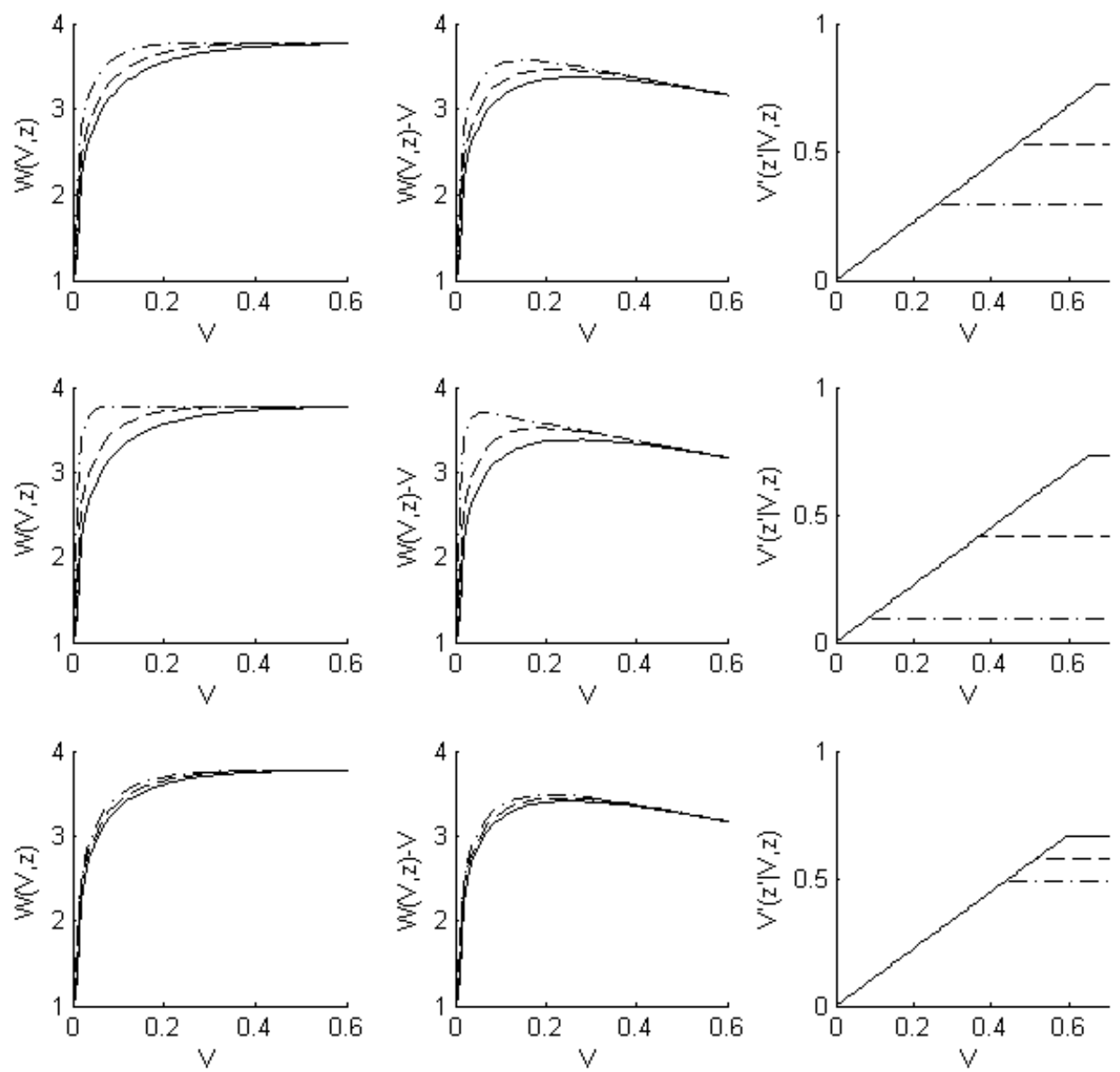

High Intangible Share

--- Medium Intangible Share $-\cdot-\cdot-$ Low Intangible Share 
To illustrate how identification results from properties of the model, I plot the value and policy functions of the model using parameter values in Table 5 except $\eta_{k}=0.3$ and $\eta_{a}=0.95$. The upper left panel of Figure 7 plots total surplus value $W$ as a function of $V$ for firms with a low current $z$, for firms with a high, medium and low share of intangible assets (i.e., $\gamma=0.05,0.45$, and 0.85 ) respectively. ${ }^{37} \mathrm{~W}$ is strictly increasing and strictly concave in $V$ until $V$ reaches the threshold value: the efficient frontier $\tilde{V}(\gamma)$. For any given value of $V$ smaller than the threshold value, the rate of change in $W$ with respect to $V$ is larger for firms with higher $\gamma$.

The upper middle panel of Figure 7 plots $B$ as a function of $V$. The model predicts that as $V$ increases, $B$ decreases more than one-to-one with respect to $V$ as a result of postponing dividend payment until $V=\tilde{V}(\gamma)$. In the graph, the highest level of $B$, which I shall call $\bar{B}(\gamma)$, is the maximum debt value that can be achieved under the optimal contract. If $\bar{B}(\gamma) \geq I_{0}$, then the optimal contract picks $B_{0}(\gamma)=I_{0}$; otherwise no contract can be arranged that satisfies debtholders' initial incentive constraint $B_{0}(\gamma) \geq I_{0}$. The graph shows that $\bar{B}(\gamma)$ is increasing in $\gamma$, suggesting that firms with a high share of physical capital can sustain a larger initial debt. For any $I_{0}$ that satisfies $\bar{B}(\gamma) \geq I_{0}$, the initial value to shareholders satisfies $B_{0}\left(V_{0}\right)=I_{0} \cdot{ }^{38}$ Also evident from the graph is the monotonicity of $V_{0}(\gamma)$ in $\gamma$ : firms with a higher share of physical assets have higher $V_{0} .{ }^{39}$ The upper right panel of Figure 7 plots the continuation value $V^{\prime}\left(z_{l}\right)$ as a function of $V$ for firms with a low current $z$. For all three values of $\gamma, V^{\prime}(\gamma)$ increases at a constant rate until $V$ reaches a threshold value $\tilde{V}(\gamma)$. This threshold value is higher for firms with a higher share of intangible assets, reflecting their more restrictive borrowing constraints. In a region where $V \geq \tilde{V}(\gamma), V$ is not relevant for the total surplus. Many payment schedules are possible. Here, I illustrate the case in which the firm pays interests and keeps the value to debtholders constant. ${ }^{40}$

To illustrate the effect of a decrease in financial frictions, the middle panels of Figure 7 plot value function and policy rules with a different parameterization: $\eta_{k}=0.05$ and $\eta_{a}=0.95$. Compared to the previous parameterization, financial frictions are lower for all firms but firms with a low share of intangible assets are most affected. These firms also reach the efficient frontier much sooner and have a higher $\bar{B}(\gamma)$. Finally, to illustrate the effect of a decreased spread between the repudiation value of intangible assets and physical assets, I set $\eta_{k}=0.5$ and $\eta_{a}=0.75$ and plot the results in the lower panels of Figure 7. As expected, this change reduces the differences between firms. For example, the efficient frontier $\tilde{V}(\gamma)$ are closer between firms with different shares of intangible assets. The variation in entrant value $V_{0}$ is also smaller.

\footnotetext{
${ }^{37}$ For more compact notation, I shall suppress the argument $z$ in the rest of this subsection.

${ }^{38}$ For any $I_{0} \leq \bar{B}(\gamma)$, the $I_{0}$ line crosses $B(V, \gamma)$ twice as a result of the concavity of $B(V, \gamma)$ in $\gamma$. The optimal contract corresponds to the one with higher $V$ because $V$ satisfies $V=\sup \left\{V: B\left(V_{0}, z_{0}\right) \geq I_{0}\right\}$.

${ }^{39}$ Strictly speaking, this results holds when $I_{0}$ is high. When $I_{0}$ is sufficiently low, $V_{0}(\gamma)$ is the same for all $\gamma$. This the case when the initial debt is so low that the financial constraint does not bind for an entrant firm.

${ }^{40}$ To see this, recall that $W(V, \gamma)$ is constant in $V$ in a region where $V \geq \tilde{V}(\gamma)$. Constant $B$ then implies constant $V$.
} 


\section{References}

Albuquerque, Rui, and Hugo A. Hopenhayn, 2004, "Optimal Lending Contracts and Firm Dynamics," Review of Economic Studies, Vol. 71, No. 2 (04), pp. 285-315.

Arellano, Cristina, Yan Bai, and Jing Zhang, Forthcoming, "Firm Dynamics and Financial Development," Journal of Monetary Economics.

Atkeson, Andrew, and Patrick J. Kehoe, 2005, "Modeling and Measuring Organization Capital,” Journal of Political Economy, Vol. 113, No. 5 (October), pp. 1026-1053.

Clementi, Gina Luca, and Hugo A Hopenhayn, 2006, "A Theory of Financing Constraints and Firm Dynamics,” The Quarterly Journal of Economics, Vol. 121, No. 1 (02), pp. 229-265.

Cooley, Thomas F., and Vincenzo Quadrini, 2001, "Financial Markets and Firm Dynamics," American Economic Review, Vol. 91, No. 5 (December), pp. 1286-1310.

Corrado, Carol A., Charles R. Hulten, and Daniel E. Sichel, 2006, "Intangible Capital and Economic Growth,” NBER Working Papers 11948, National Bureau of Economic Research, Inc, ).

E., Jr Lucas Robert, 1978, "On the Size Distribution of Business Firms,” Bell Journal of Economics, Vol. 9, No. 2 (Autumn), pp. 508-523.

Eisfeldt, Andrea L., and Dimitris Papanikolaou, Forthcoming, "Organization Capital and the Cross-Section of Expected Returns," Journal of Finance.

Evans, David S, 1987, "Tests of Alternative Theories of Firm Growth," Journal of Political Economy, Vol. 95, No. 4 (August), pp. 657-74.

Falato, Antonio, Dalida Kadyrzhanova, and Jae W. Sim, 2013, "Rising Intangible Capital, Shrinking Debt Capacity, and the US Corporate Savings Glut," Finance and Economics Discussion Series, Federal Reserve Board, ).

Fama, Eugene F., and Kenneth R. French, 1997, "Industry costs of equity," Journal of Financial Economics, Vol. 43, No. 2 (February), pp. 153-193.

Fazzari, Steven M., R. Glenn Hubbard, and Bruce C. Petersen, 1988, "Financing Constraints and Corporate Investment," Brookings Papers on Economic Activity, Vol. 19, No. 1, pp. 141-206.

Gomes, Joao F., 2001, “Financing Investment," American Economic Review, Vol. 91, No. 5 (December), pp. 1263-1285.

Hall, Bronwyn H, 1987, "The Relationship between Firm Size and Firm Growth in the U.S. Manufacturing Sector," Journal of Industrial Economics, Vol. 35, No. 4 (June), pp. 583606. 
Haltiwanger, John C., Ron S. Jarmin, and Javier Miranda, 2010, "Who Creates Jobs? Small vs. Large vs. Young," NBER Working Papers 16300, National Bureau of Economic Research, Inc, ).

Hayashi, Fumio, 1982, "Tobin's Marginal q and Average q: A Neoclassical Interpretation," Econometrica, Vol. 50, No. 1 (January), pp. 213-24.

Hopenhayn, Hugo A, 1992, "Entry, Exit, and Firm Dynamics in Long Run Equilibrium," Econometrica, Vol. 60, No. 5 (September), pp. 1127-50.

Jovanovic, Boyan, 1982, "Selection and the Evolution of Industry," Econometrica, Vol. 50, No. 3 (May), pp. 649-70.

Kiyotaki, Nobuhiro, and John Moore, 1997, "Credit Cycles," Journal of Political Economy, Vol. 105, No. 2 (April), pp. 211-48.

Laitner, John, and Dmitriy Stolyarov, 2003, "Technological Change and the Stock Market," American Economic Review, Vol. 93, No. 4 (September), pp. 1240-1267.

Lev, Baruch, 2001, Intangibles: Management, Measurement, and Reporting (Washington, DC: Brookings Institution Press).

and Suresh Radhakrishnan, "The Valuation of Organization Capital," 2005, in "Measuring Capital in the New Economy" NBER Chapters (National Bureau of Economic Research, Inc), pp. 73-110.

McGrattan, Ellen R., and Edward C. Prescott, 2000, "Is the stock market overvalued?," Quarterly Review, No. Fall, pp. 20-40.

Meyer, John Robert, and Edwin Kuh, 1957, The Investment Decision: An Empirical Study (Cambridge, MA: Harvard University Press).

Quadrini, Vincenzo, 2004, "Investment and liquidation in renegotiation-proof contracts with moral hazard," Journal of Monetary Economics, Vol. 51, No. 4 (May), pp. 713-751.

Stein, Jeremy C., "Chapter 2 Agency, information and corporate investment," 2003, in M. Harris G.M. Constantinides, and R.M. Stulz, eds., Corporate Finance, Vol. 1, Part A of Handbook of the Economics of Finance (Elsevier), pp. 111 - 165.

Stokey, Nancy L., Robert E. Lucas, and Edward C. Prescott, 1989, Recursive Methods in Economic Dynamics (Cambridge, MA: Harvard University Press).

Summers, Lawrence H., 1981, "Taxation and Corporate Investment: A q-Theory Approach," Brookings Papers on Economic Activity, Vol. 12, No. 1, pp. 67-140. 